Portland State University

PDXScholar

5-7-1993

\title{
A Model to Predict Recycling Behaviors: Reusing Ajzen's Model One More Time
}

Kathleen L. Kiwala

Portland State University

Follow this and additional works at: https://pdxscholar.library.pdx.edu/open_access_etds

Part of the Psychology Commons

Let us know how access to this document benefits you.

\section{Recommended Citation}

Kiwala, Kathleen L., "A Model to Predict Recycling Behaviors: Reusing Ajzen's Model One More Time" (1993). Dissertations and Theses. Paper 4607.

https://doi.org/10.15760/etd.6491

This Thesis is brought to you for free and open access. It has been accepted for inclusion in Dissertations and Theses by an authorized administrator of PDXScholar. Please contact us if we can make this document more accessible: pdxscholar@pdx.edu. 
AN ABSTRACT OF THE THESIS OF Kathleen L. Kiwala for the Master of Science in Psychology presented May 7, 1993.

Title: A Model to Predict Recycling Behaviors: Reusing Ajzen's Model One More Time

APPROVED BY THE MEMBERS OF THE THESIS COMMITTEE:

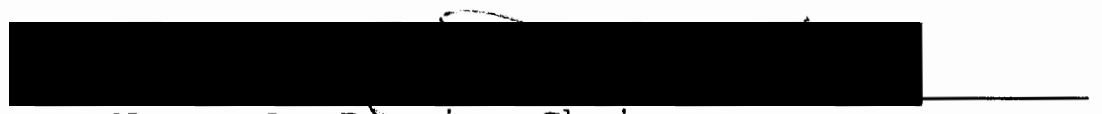

Nancy A. Pexcin, Chair
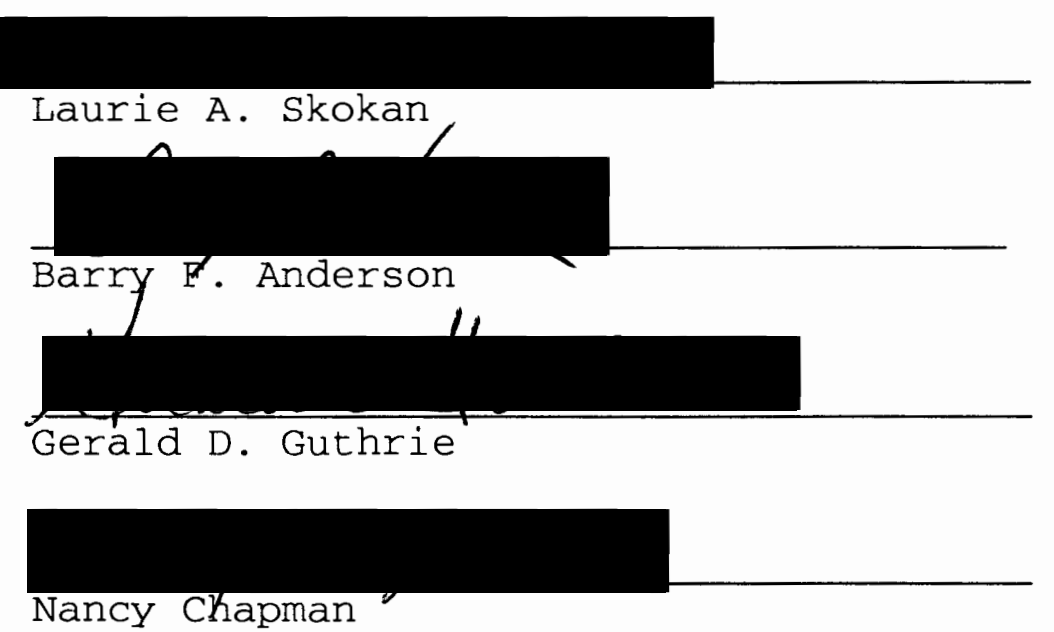

The prediction of self-reported recycling behaviors was examined using variations and expansions of Ajzen's theory of planned behavior. Three hundred and forty-eight residents from the Multnomah, Clackamas and Washington counties in oregon completed a questionnaire that assessed attitude, subjective norms, perceived behavioral control, intentions, self-reports of recycling behavior, moral 
obligation and past behavior. Recycling behaviors and intentions were grouped into three categories of difficulty by a factor analysis. Structural equation analysis did not support Ajzen's model. It was found that although attitudes was correlated with the antecedent variables, it did not directly influence intentions or behaviors. Perceived behavioral control had the largest direct influence on behavior. Subjective norms had the greatest direct influence on intentions. Past behavior, as measured, was not significantly related to any variable in the model. The inclusion of moral obligation added significantly to the ability to predict recycling behavior. Moral obligation directly influenced subjective norms, attitude, perceived behavioral control and behavior. The results suggest that programs that aim to increase recycling behaviors should focus on: the community good as the motivation for recycling, the impacts of the individual's recycling behavior on community resources, the "how to's" of recycling, and supplying services and information about those services. 
A MODEL TO PREDICT RECYCLING BEHAVIORS:

REUSING AJZEN'S MODEL ONE MORE TIME

by

KATHLEEN L. KIWALA

A thesis submitted in partial fulfillment of the requirements for the degree of

MASTER OF SCIENCE

in

PSYCHOLOGY

Portland State University

1993 
TO THE OFFICE OF GRADUATE STUDIES:

The members of the Committee approve the thesis of Kathleen L. Kiwala presented May 7, 1993.

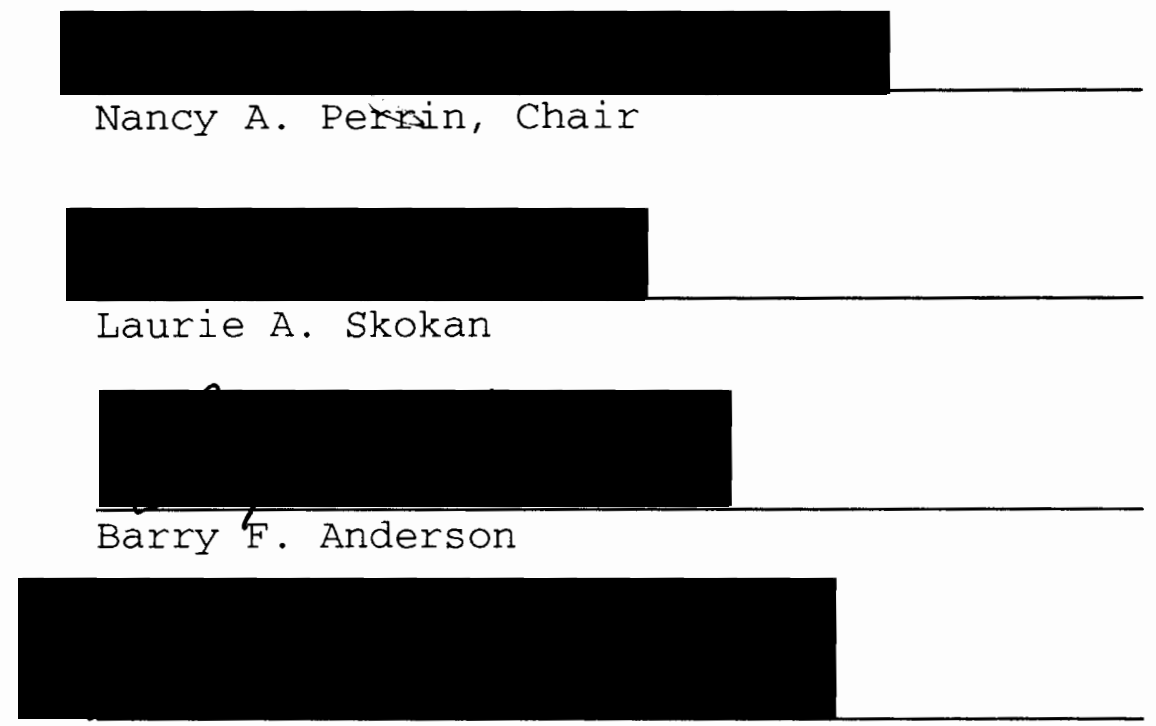

Gerald D. Guthrie

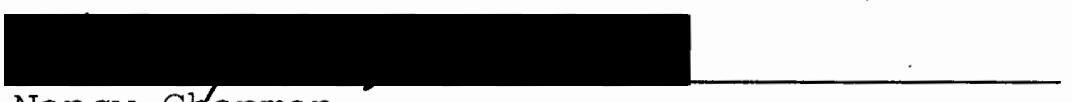

Nancy Clkapman

APPROVED:

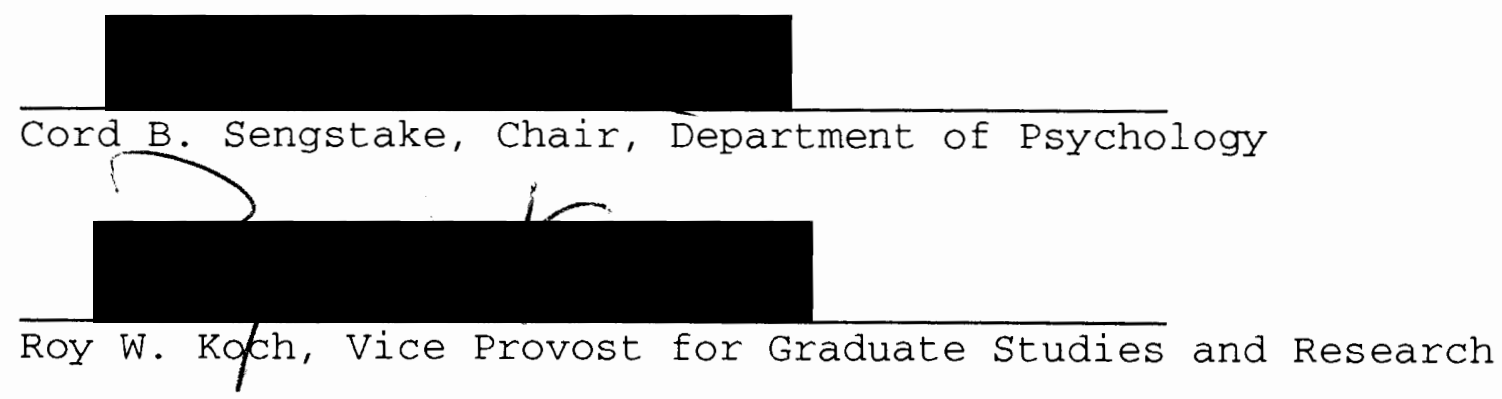




\section{ACKNOWLEDGEMENTS}

There are many people who have encouraged and helped me through the arduous experience of my Master's thesis. Without those people, this work would never have become reality. I would like to express my gratitude to those people.

My warmest thanks and deepest appreciation are for Dr. Nancy Perrin, my advisor and thesis chair, who gave so freely of her time and was invaluable in the design and analysis of the data. Her continuous encouragement, enthusiasm and demand for quality were significant factors in the completion of this study.

My gratitude is also due to the members of my committee: to Laurie Skokan, who originally spurred this paper into a thesis project, for her support and suggestions, to Barry Anderson for his enthusiasm and ideas throughout the project, and to Gerry Guthrie, for his sustained interest and support.

A special thanks to Marcus Daniels, for his work with the data, his computer assistance and his encouragement.

Finally, a loving thank you goes to my daughters, Jessica and Megan, who were understanding and supportive when I was experiencing the highs and lows of completing a thesis and being too busy. 
TABLE OF CONTENTS

PAGE

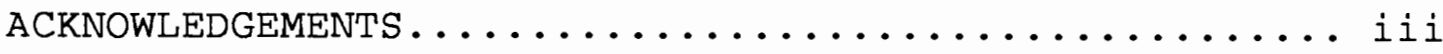

LIST OF TABLES........................... vi

LIST OF FIGURES....................... vii

CHAPTER

I INTRODUCTION..................... 1

Recycling as a Commons Dilemma.......4

A Model of Behavior.............. 6

Values and Recycling............ 20

Research Goals................. 21

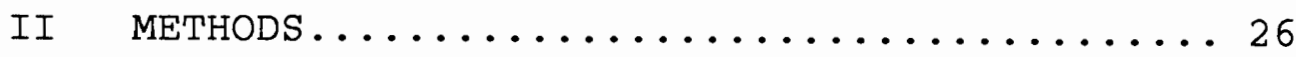

Subjects and sampling........... 26

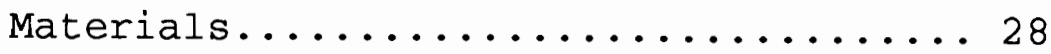

Procedure........................... 31

III ANALYSIS....................... 32

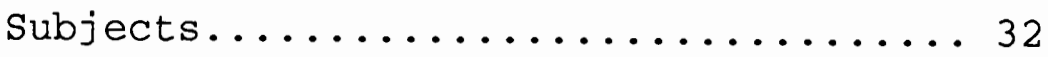

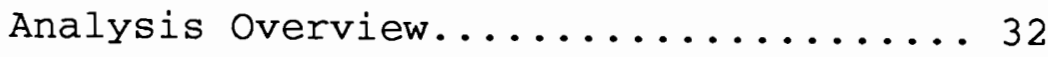

Assessment of Goodness-of-Fit....... 38 
IV $\quad$ RESULTS...................... 40

Descriptive Statistics...........4 40

Steps of the Analysis............44

Test of the Structural Models....... 50

$\mathrm{V} \quad$ DISCUSSION......................... 60

The Measurement of Moral Obligation....6 61 Structural Models..............66 62

Application of the Results........6 69

Criticisms of the study...........71

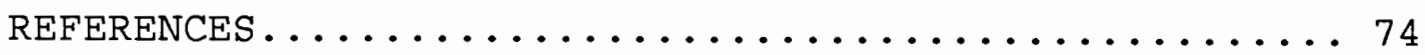

APPENDIX........................... 80 


\section{LIST OF TABLES}

TABLE

PAGE

I Description of Sample, in Percentages........4 41

II The Standardized Factor Loadings for

Confirmatory Factor Analysis of the

Moral Obligation Variable............44

II Rotated Pattern Factor Matrix for Subjective

Norms and Percentages of Accounted

Variance.........................44

IV Rotated Pattern Factor Matrix for Recyclable

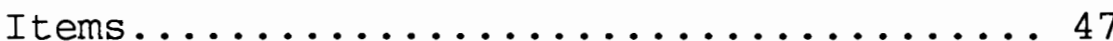

V Lambda X Matrix with the Final Values of the

Factor Loadings for the Measurement

Model.......................... 49

VI Correlation Among Latent Variables.......... 50

VII Chi-Squares, Degrees of Freedom, AGFI, PGFI

and RMS for Models Tested............ 56

VIII Squared Multiple Correlations for Behavior and Intentions in All Models............ 59 
LIST OF FIGURES

FIGURE

PAGE

1. Ajzen's Theory of Planned Behavior.......... 7

2. Possible Influence of Past Behavior in Ajzen's

Theory of Planned Behavior Model........ 16

3. Possible Roles of Self-Centered and Society-

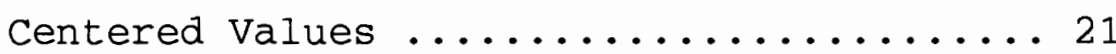

4. Ajzen's Simultaneous Model............... 22

5. Variation of Ajzen's Model.............. 23

6. Simultaneous Test of All Variables.......... 25

7. Latent Constructs and Their Associated

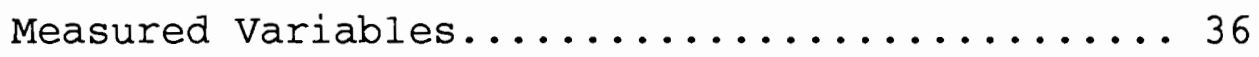

8. Expanded Simultaneous Model............... 37

9. The Expanded Variation Model............... 38

10. Standardized Path Coefficients and Correlations of the Final Ajzen's Simultaneous Model... 51

11. Standardized Path Coefficients and Correlations of the Final Variation of Ajzen's Model... 53

12. Standardized Path Coefficients and Correlations

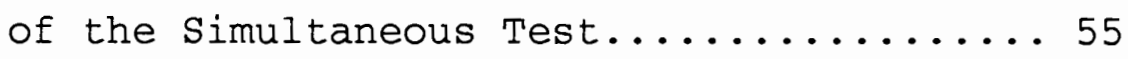

13. Standardized Path Coefficients and Correlations of the Expanded Simultaneous Model....... 58

14. Standardized Path Coefficients and Correlations of the Expanded Variation Model......... 58 
CHAPTER I

\section{INTRODUCTION}

Concerned citizens, policy makers, and researchers are increasingly interested in finding ways to encourage others to modify their behaviors to save the environment. New technologies have been developed to address some of our environmental problems, however they often produce their own negative side effects. To use these new technologies efficiently, it frequently is necessary for people to learn a new set of behaviors or change existing behaviors. Therefore, to help the environment, researchers need to focus attention on strategies which encourage behavior changes.

One good example of a type of behavioral change needed to improve the environment is recycling. Recycling involves collecting various types of reusable materials which could be reprocessed, manufactured, and sold. Recycling technologies result in the preservation of our remaining resources and decreased volumes of garbage sent to ever-diminishing landfills. The recycling system depends upon the cooperation of manufacturers, consumers, and reprocessing plants. Many groups and garbage collection companies provide containers and services to collect 
recyclable items, such as glass, newspapers, plastics, and metals. To make the system effective, people must perform a certain set of behaviors such as selecting, cleaning, and storing their recyclables properly. They need to stop throwing out recyclable items, even though it is a quicker and easier option.

Currently, researchers and government policy makers are trying to study and change people's behaviors that contribute to our deteriorating environment. Established behaviors that have an adverse effect on the environment need to be replaced with new behaviors that can help save and protect the environment. Some of these behavior changes will involve substantial modifications of everyday life.

Education (Allen, 1972; Cohen, 1973; Asch \& Shore, 1975), various reinforcement strategies (Deslauriers \& Everett, 1977; Winett \& Nietzel, 1975; Geller et al., 1982; Hayes \& Cone, 1977a), prompts and cues (Geller, et al., 1982; Hayes \& Cone, 1977b) and feedback (Kohlenberg et al., 1976; Schnelle et al., 1980), are methods that have been applied to attempt change in people's preferences, attitudes and pro-ecological behaviors. All have met with limited success.

Research studies have examined people's attitudes toward recycling (DeYoung, 1985-86). Environmental education programs have attempted to increase awareness and knowledge, in addition to changing attitudes (Allen, 1972; 
Cohen, 1973). However, providing information, increasing knowledge and changing attitudes are often insufficient to produce a behavioral change. From past research, it appears that the link between environmental education and behavior is weak (Cone \& Hayes, 1980). Perhaps a model of recycling behavior, based upon the specific behavioral acts and their antecedents, would provide a more complete outline and aid in designing interventions to promote change.

Researchers have looked for ways to change people's behaviors by examining factors that may precede and influence a behavioral act. Applying models of behavior that describe underlying factors and their relationships have been useful in designing and implementing interventions. For example, education or promotion programs could better influence behavior by aiming at changing a specific underlying factor of the behavioral response. If knowledge about a particular behavior is lacking, education can focus upon increasing the skills necessary to perform that behavior. Or, if an attitude toward a behavior is negative, perhaps information or positive experiences with the behavior could be given. There are a variety of models of the antecedents of behavior that have been substantiated with different types of behaviors. 
RECYCLING AS A COMMONS DILEMMA

Recycling can be viewed as a commons dilemma (Platt, 1973), where behaviors that are good for the individual and are instigated by self-serving motives, are bad for the collective. It is advantageous for an individual to throw away all their garbage, in terms of time and energy--it is quicker and easier to do so. However, it would be disastrous if all individuals did this; natural resources would be depleted and landfills would overflow. Although the destructive behavior by one individual has little impact on the whole, if all people engage in the same individual behavior, the impact on the commons is disastrous.

Platt (1973) notes that behaviors can be analyzed in terms of their associated reinforcements (rewards and punishments). There is a positive aspect of the situation which people seek, and a negative aspect which people seek to avoid. The problem is that these reinforcements become separated from the behavior in time, or when the negative reinforcement is diluted across the members of a group (Platt, 1973). This makes actions that lead to short-term positive behavior and long-term negative consequence more likely to occur. For example, the immediate reward of throwing out all your garbage is more salient than the longterm negative consequence that occurs when everyone throws out all of their garbage. Because the punishment is shortterm, and the reward is long-term, we avoid performing the 
behavior. In this case, we avoid sorting, cleaning, and storing recyclables because the inconvenience masks the long-term benefits of an environment with adequate resources and sufficient places to dispose garbage.

Laboratory studies have found that adding rewards for cooperative behaviors and punishments for selfish behavior helps preserve the commons (Bel1, Peterson, \& Hautaluoma, 1989; Komorita, 1987; Yamagishi, 1986). Other commons dilemma studies have found that cooperation and trust are essential for positive collective outcomes in the commons dilemma (Edney, 1979; Moore et al., 1987). When players were given time to study the game and communicate, they tended to come up with their own strategies for cooperative behaviors, which were often pro-ecological.

Although these are all laboratory studies, there are some implications for how we can approach the problem of changing people's behaviors in the commons dilemmas of the real world. However, it is apparent that there is more involved in individuals' behaviors than rewards and punishments. Reinforcement theory, which can be adapted for individuals, does not easily accomodate itself to the variability of groups of individuals. This is well supported in most areas of psychological research (Edney, 1980). There are different responses from individuals to certain rewards and punishments. Also missing from behavior reinforcement explanations are the influences of moral 
beliefs or ethics, perceptions about group norms and group pressure to conform, attitudes, and perceptions about one's own ability to perform a behavior. Studies have found that information (Edney \& Harper, 1978), identification with others (Brewer \& Kramer, 1986), and some influence by one's sense of moral obligation (Gorsuch \& Ortberg, 1983) play a part in one's behaviors.

\section{A MODEL OF BEHAVIOR}

Ajzen $(1985,1987)$ has developed a model which attempts to explain a person's tendency to perform, or not perform, a particular behavior. His Theory of Planned Behavior (TPB), which is belief-based, finds that attitudes, subjective norms, and perceived behavioral control are the determinants of intentions which then determine specific behaviors. Beliefs and the evaluation of those beliefs are the antecedents of the three initiating factors.

According to Ajzen's theory, intentions and behavior are a function of the beliefs or salient information relevant to the behavior. Beliefs concerning the likely outcomes (consequences) of a behavior and subjective evaluations of those outcomes determine whether a favorable or unfavorable attitude toward performing the behavior is held. Subjective norms are measured by the person's beliefs about the normative expectations of salient referent individuals, and the motivation to comply with these 
referents. Beliefs about factors that can prevent or facilitate attainment of, or attempts to attain goals produce a perception about a certain level of behavioral control. In Ajzen's model (see Figure 1) these three variables of attitudes, subjective norms, and perceived behavioral control influence a person's intentions to perform behaviors and behavior is a function of intended behavior (intentions) and perceived behavioral control.

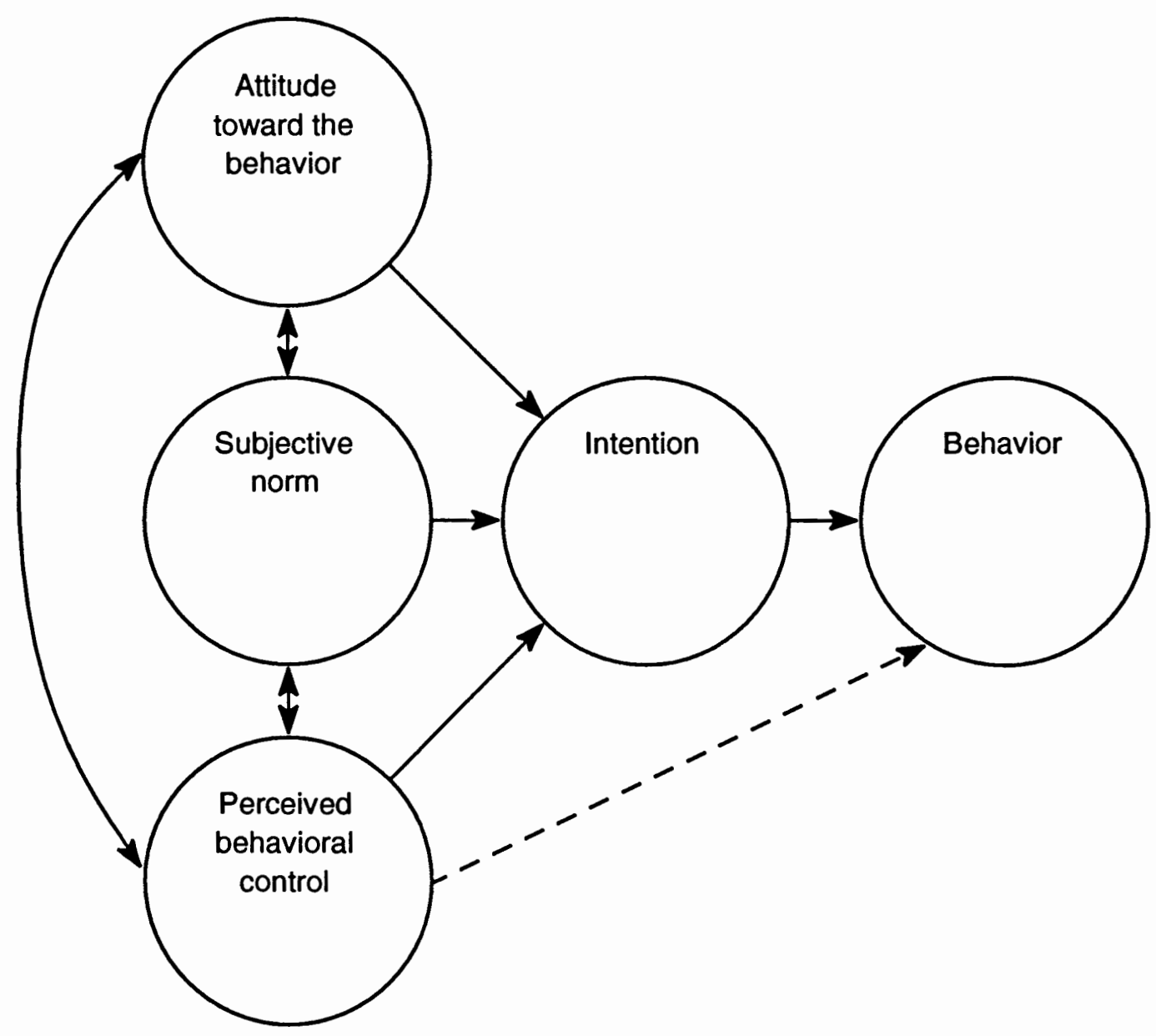

Figure 1. Ajzen's Theory of Planned Behavior. 
The components of the TPB

Attitudes. Attitudes toward a behavior have been found to correlate well with the behavior. The attitude factor in Ajzen's model is based upon two components: a behavioral belief and an evaluation of behavior outcomes. Behavioral beliefs are simply salient beliefs about that behavior. Each behavioral belief links the behavior to a certain outcome, or to some other attribute of the performance of the behavior. For example, individuals may believe that recycling all their cans, papers, and bottles (the behavior) will reduce their garbage output and their garbage bill, preserve natural resources, and take up some free time, (outcomes).

The attitude towards a behavior is determined by the individual's positive or negative evaluation of the outcomes associated with performing the particular behavior, and the strength of those associations (Ajzen, 1988, p. 120). An estimate of the attitude toward a behavior can be obtained by summing the product of each belief strength and its outcome evaluation. Another way to gain an estimate of a person's attitude is to obtain direct ratings of evaluative adjectives about a certain behavior. If a person believes that performing a certain behavior will lead to mostly negative outcomes, that person will hold an unfavorable attitude toward the behavior, the opposite holds true for favorable attitudes. 
Among all the antecedents of behavior specified in the TPB (attitudes, perceived norms, perceived behavioral control) it is attitudes which usually has the greatest causal influence on behavior (Ajzen, 1971; Manstead et al., 1983; King, 1975; Ajzen \& Fishbein, 1980). In general, studies have found that people are likely to perform a specific behavior if they view its probable outcomes favorably.

Subjective Norms. Another determinant of behavioral intentions is subjective norms (SN), which is a measure of a person's perception of social pressure to perform or not perform a particular behavior. People are generally more likely to perform a certain behavior when they believe that referent others, such as parents, spouse, coworkers, friends, and perhaps experts, think they should perform it. In the TPB, attitudes and SN are often both equally important in making significant contributions to the prediction of behavioral intentions. In making a decision to join an alcoholic treatment unit (Ajzen \& Fishbein, 1980), the correlations of attitude and SN with behavioral intention was found to be 0.69 and 0.67 , respectively. Depending on the behavior under question, one or the other predominates. In most studies using this model, attitudes carried a higher weight in predicting intentions than did SN. In choosing between breast-vs. bottle-feeding (Manstead et al., 1983), attending church (King, 1975), 
smoking marijuana (Ajzen et al., 1982), attitudes carried a higher weight than SN. However, in studies looking at women's decision to have an abortion (Smetana \& Adler, 1980), and a couple's decision to have another child (Vinokur-Kaplan, 1978), SN, or the perception of social pressure, more strongly influenced the intention.

A measure of subjective norms can be attained in two ways. One method is to obtain measures of individuals' belief concerning each referent and their motivation to comply with each of the referents. Subjective norms are then the sum of each belief multiplied by each motivation to comply. Another more direct measure of subjective norms is to ask respondents to judge how likely it is that most people who are important to them would approve of their performing a given behavior.

Perceived Behavioral control. Ajzen's concept of perceived behavioral control (PBC) is closely related to Bandura's concept of self-efficacy $(1977,1982)$. PBC is simply the amount of control one perceives that he or she has over performing a certain behavior. If the required opportunities and resources are available, the perceived level of behavioral control should be high. If opportunities and resources necessary to perform the behavior are absent, the level of behavioral control would be perceived as being low. 
There are internal factors which affect the level of PBC. Lack of information, skills, and abilities may create barriers and failures for someone attempting to perform a behavior. Often, these internal factors may be changed by training and experience.

External factors are situational or environmental factors which may be disruptive to performing a behavior (e.g., becoming too ill to perform daily cooking, cleaning, and recycling chores). In this instance, an unanticipated event brings about changes in immediate intentions, but not changes in attitude or subjective norms (Ajzen, 1987). Environmental factors may actually prevent the behavior, for example, if there is no recycling service or center available to an individual. Dependence upon the actions of others to perform a certain behavior also leads to incomplete control over behavioral goals.

These internal and external factors are actual control factors over behaviors. A person will consider all these factors when attempting to determine the ease or difficulty of performing a certain behavior. The resulting perceived level of behavioral control is also assumed to be influenced by past experience.

In TPB, perceived behavioral control is assumed to affect the motivational levels of intentions, and when the behavior is not completely volitional, PBC can possibly affect behavior directly, since it "may be considered a 
partial substitute for a measure of actual control" (Ajzen, 1988, p.134). In Figure 1, the broken line between PBC and behavior indicates the potential relationship which can exist when the behavior is not completely volitional.

To obtain a direct measure of a respondent's PBC for certain behaviors, people are is usually asked to rate how easy or difficult they consider performance of specific behaviors, and if practice of the behavior will accomplish what the behavior is said to accomplish (e.g. by recycling, one could reduce the amount of garbage contributed to the community waste stream). The ratings on these items are summed to yield a measure of $\mathrm{PBC}$.

When $\mathrm{PBC}$ is refined to look at specific behavioral responses, its correlation with actual performance of the behaviors becomes stronger. In general, people's attempt to perform a behavior is commensurate with the amount of confidence they have in their ability to actually do so. In general, as people become more capable of performing the behavior, their attempts will be more successful. A study looked at women's performance of breast self-examination, their PBC about the behavior, and a measure of their proficiency at the behavior (Alagna \& Reddy, 1984). The correlation of $P B C$ with the frequency of self-examinations (in the 6-months previous to the measurements) was 0.45 ; the correlation of proficiency at the behavior with the actual performance of the behavior was 0.57 . 
Intentions. A behavioral intention is the motivational result of the antecedent variables attitudes, SN, PBC, and past behaviors. An intention is an indicator of how hard a person is willing to try and how much effort they are willing to invest in performing that behavior. Behavioral intentions should correlate highly with behaviors actually performed, unless there is some intervening event, or too much time has passed. Intentions can give a highly accurate prediction of the actual performance or non-performance of the intended behavior in situations when the act is under volitional control. For example, high multiple correlations between intentions and behaviors $(0.84)$ were found in studies on voting choice (Ajzen, 1991), and leisure activities (0.78; Ajzen \& Driver, 1992). If people are free to perform a behavior, it is most likely that they will do what they intend to do.

Studies have found strong intention-behavior correlations. The correlations have ranged from 0.72 to 0.96 for behaviors such as smoking marijuana (Ajzen et al., 1982), voting choice (Ajzen \& Fishbein, 1980) and having an abortion (Smetana \& Adler, 1980). When behavioral goals are not completely under volitional control (e.g., losing weight and getting an "A" in a course), $\mathrm{PBC}$ is found to correlate with intentions, influencing intentions to pursue or not pursue the behavioral goals (Schifter \& Ajzen, 1985; Ajzen \& Madden, 1986). 
Intentions are measured by asking individuals to indicate on several Likert scales their intention to perform a certain behavior and the intensity of that decision. Generally, people will have intentions to perform certain behaviors when they hold favorable evaluations (attitude) of the outcomes, when they think that referent others will approve of it, and if they think they have the resources and opportunities available to perform the behavior.

\section{Support for the Model}

The Theory of Planned Behavior has been well supported by empirical evidence, however the model performs better predicting certain types of behaviors. For example, the $R^{2}$ for the model applied to lying, shoplifting and cheating varies between 0.12 to 0.55 for behavior and between 0.33 to 0.61 for intentions (Beck \& Ajzen, 1991). The $\mathrm{R}^{2}$ for the model applied to leisure choices varied between 0.25 to 0.33 for behavior and between 0.37 to 0.52 for intentions (Ajzen \& Driver, 1992). The variance accounted for in behavior for losing weight varies between 0.23 to 0.44 (Netemeyer \& Burton, 1990; Schifter \& Ajzen, 1985). The $\mathrm{R}^{2}$ for attending a class and getting an "A" in the course varied between 0.26 and 0.45 , depending on whether the measures were taken at the beginning or the end of the semester (Ajzen \& Madden, 1986). Of all behaviors that the TPB model has been applied to, these last two behaviors have the least variance 
accounted for (Ajzen, 1991). Ajzen attributes this pattern of results to a low correspondence between perceived and actual control.

Given the amounts of variance accounted for in these various behavioral domains, it appears that the model is still lacking. The inclusion of additional factors may improve prediction. In the area of behaviors to save the environment, beliefs about moral values may help to influence one's behaviors, however, other factors such as personal norms and past behaviors, should also be considered.

\section{Extensions of the TPB}

Past behavior. As first noted by Bentler and speckart (1979, 1981), when a self-report measure of past behavior was included in Fishbein's Theory of Reasoned Action (the predecessor of the TPB), there remained little unexplained variance. Bentler and Speckhart examined the relations of attitudes, subjective norms, and intentions for three different categories of behaviors. Using structural equation models to predict religious behaviors, expression of negative affect, and "summer" behaviors, they found that previous behavior may influence future intentions and subsequent behavior directly without altering attitudes or subjective norms (see Figure 2). Broken lines between PB and $\mathrm{PBC}$ and behavior in Figure 2 and all subsequent figures indicate paths hypothesized by Bentler and speckart. 


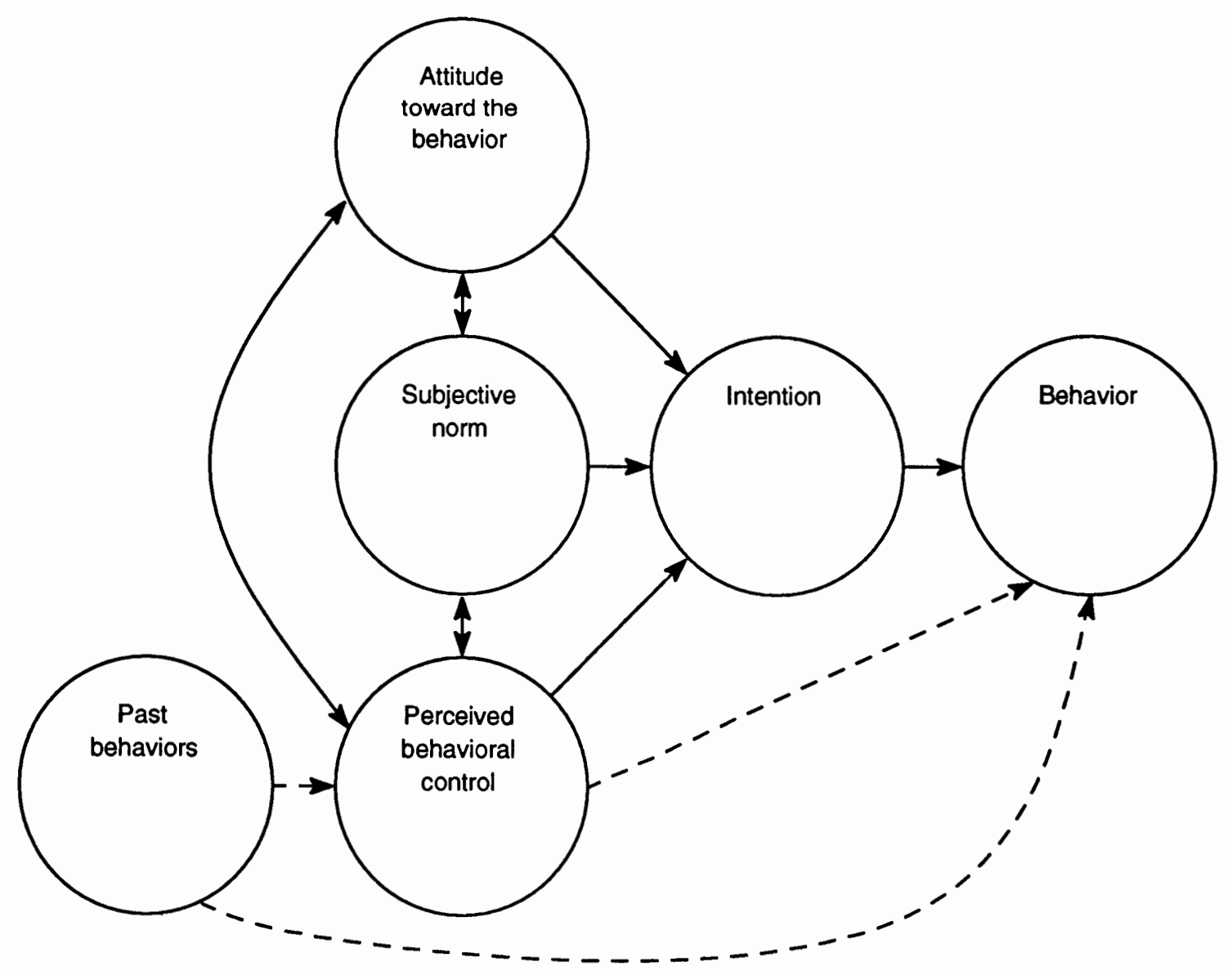

Figure 2. Possible influence of past behavior in Ajzen's Theory of Planned Behavior model.

Studies which have included Bentler and Speckart's extension of Fishbein's model have shown significant increases in the model's predictive power (Budd et al., 1984, Fredricks \& Dossett, 1983, Granrose, 1984). These theorists assume that repeated past behaviors become established habits, however Ajzen (1991) disagrees. The point of contention by Ajzen is that behaviors issue forth from habits, automatically, without the mediation of attitudes, subjective norms, perceptions of control, or 
intentions. Ajzen replies that past behaviors can be viewed as a reflection of the impact of factors that influence later behavior, but not as a causal factor (Ajzen, 1987). In essence, he says that attitudes, subjective norms, and perceived self-efficacy are residues of past experience. A correlation of any past and later behavior would be an indication of the behavior's stability (or reliability). Also, the variance contributed by past behavior could actually be common error variance shared by past behavior and later behavior.

It is possible that past behaviors' influence on future behavior is mediated by perceived behavioral control. Bandura's theory of self-efficacy (1986) points to how past behaviors impact self-efficacy. According to Bandura, past experience with a behavior is the most important source of information about behavioral control.

Studies relating to this mediation issue (Ajzen \& Driver, 1992; Beck \& Ajzen, 1991; van Ryn \& Vinokur, 1990) have predicted behaviors from intentions, perceived behavioral control, and past behaviors. The inclusion of these mediating variables still resulted in a significant amount of unexplained variance in the relationship between past behavior and future behavior. Although Ajzen believes some of the direct effect from past to future behavior is due only to method variance, he also notes that in some cases it is too large to be solely attributable to that 
cause (Ajzen, 1991). Consequently, the role of past behaviors is still unclear.

Values--Self-centered vs. Society-centered. Since recycling can be viewed as a commons dilemma, it can also be viewed as a moral situation. Recycling presents people with a choice between personal gain and yielding personal gain for the common good.

Gorsuch and ortberg (1983) found moral obligation to be a significant factor in attempting to predict behavior in "moral situations." Moral obligation was found to correlate with behavioral intentions at a higher rate than either attitudes or social norms for the moral situations. This pattern was not found in the non-moral situations. In their discussion of the results, Gorsuch and Ortberg suggest that it is important to distinguish between one's personal preferences and one's sense of moral responsibility. Even though we may prefer to do one thing, we often do another-out of a sense of moral responsibility.

Values are the determinants and guides of social behavior, ethical choices, and moral dilemmas. In his work about values, Rokeach (1973) defines a value as "an enduring belief that a specific mode of conduct or end-state of existence is personally or socially preferable to an opposite or converse mode of conduct or end-state of existence" (p. 5). 
He hypothesizes two kinds of values: terminal values, which are concerned with desirable end-states of existence, and instrumental values, which are concerned with desirable modes of conduct. Terminal values can be self-centered or society-centered. A comfortable life and pleasure are examples of self-centered terminal values. A world of beauty and brotherhood are examples of society-centered terminal values. There are also two kinds of instrumental values, moral and competence values. Moral values are what Rokeach regards as "those that have an interpersonal focus which, when violated, arouse pangs of conscience or feelings of guilt for wrongdoing" (p. 8). Competency values have a personal focus, violation of these values leads to "feelings of shame about personal inadequacy rather than to feelings of guilt about wrong doing" (p. 8).

Both kinds of values, terminal and instrumental, are organized into separate hierarchies or value systems, where values are organized along a continuum of relative importance. According to Rokeach, various clusters of values may be associated with or guide different behaviors. In a study of value systems and environmentalists by Dunlap et al. (1983, as noted in Seligman, 1989, p. 181), it was found that relative to others, people who engaged in recycling behaviors emphasized aesthetics and selfactualization and de-emphasized safety and security. These are examples of both kinds of terminal values. 


\section{VALUES AND RECYCLING}

Research on the reasons why people recycle has found that the most important reasons are intrinsic motivation and personal satisfaction (De Young, 1986; De Young \& Kaplan, 1986). It was the thought of having done something worthwhile and beneficial, not the economic advantage, that the pro-environmental respondents mentioned most often. Davidson-Cummings (1977) found that recyclers described their motivation to recycle in moral and altruistic terms. Hopper and Nielsen (1991) found that people conceptualize recycling as a type of altruistic behavior. In addition, they found that experimental interventions which attempted to influence individuals' awareness of consequences and attribution of consequences increased the level of recycling .

The inclusion of personal and societal values into Ajzen's model should increase prediction accuracy. These values may affect attitude, subjective norms, and intentions (see Figure 3). Research into recycling lends support to a strong moral component of recycling behavior. One goal of the present study was to validate the contribution of moral obligation within the context of a larger model of recycling behavior. 


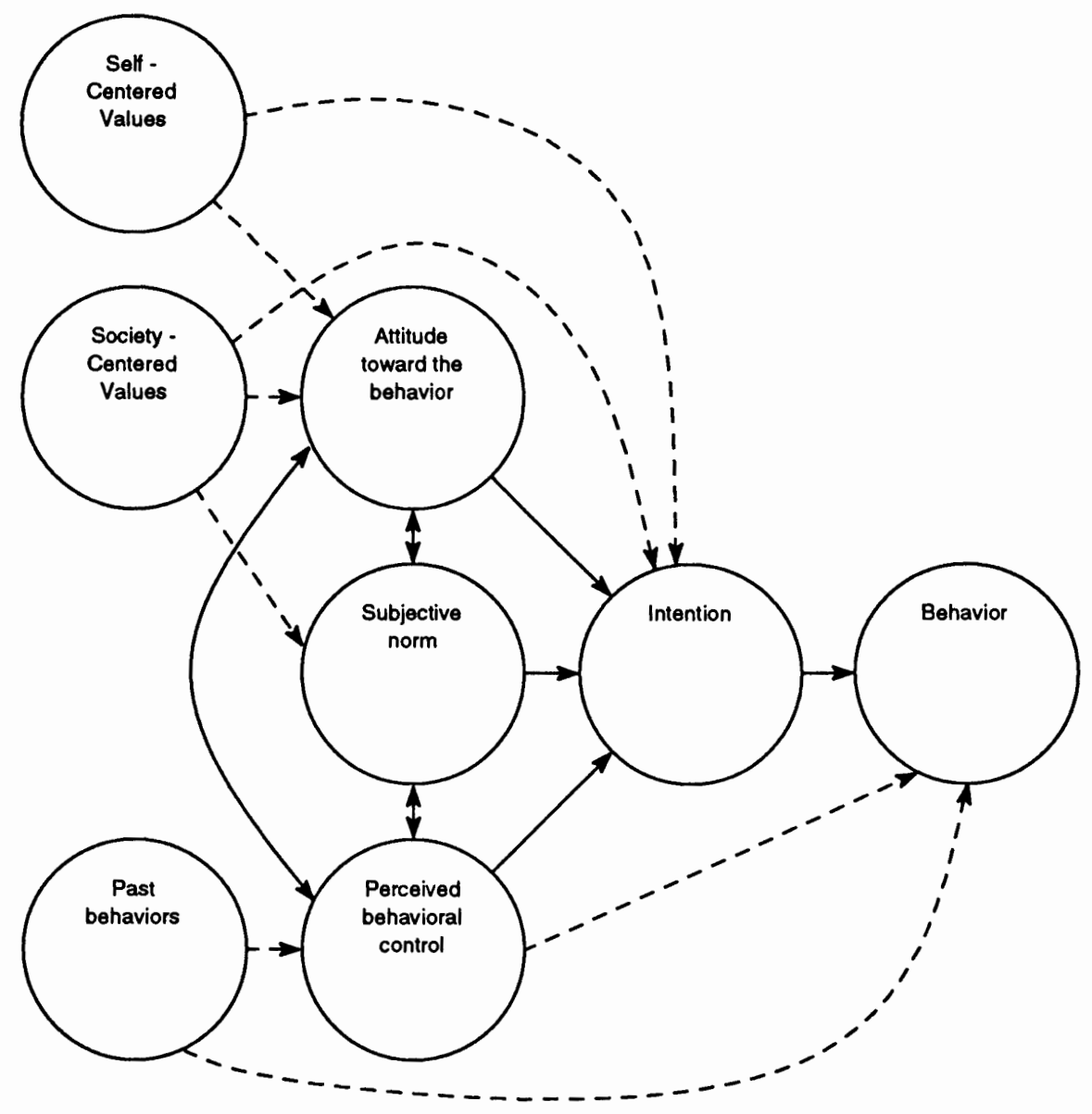

Figure 3. Possible roles of self-centered and society-centered values.

\section{RESEARCH GOALS}

This study examined several questions. First, can the TPB be used to predict recycling behaviors and intentions? Since many recycling behaviors and opportunities are new to people, and since there is a fair amount of social pressure to recycle, the factors contained in this model are appropriate to the prediction of recycling behavior. 
Attitude, subjective norms and perceived behavioral control were used to predict behavioral intentions and recycling behaviors. Since intentions and behaviors were measured at the same point in time, two variations of Ajzen's model were tested. The first model (see Figure 4) tested the

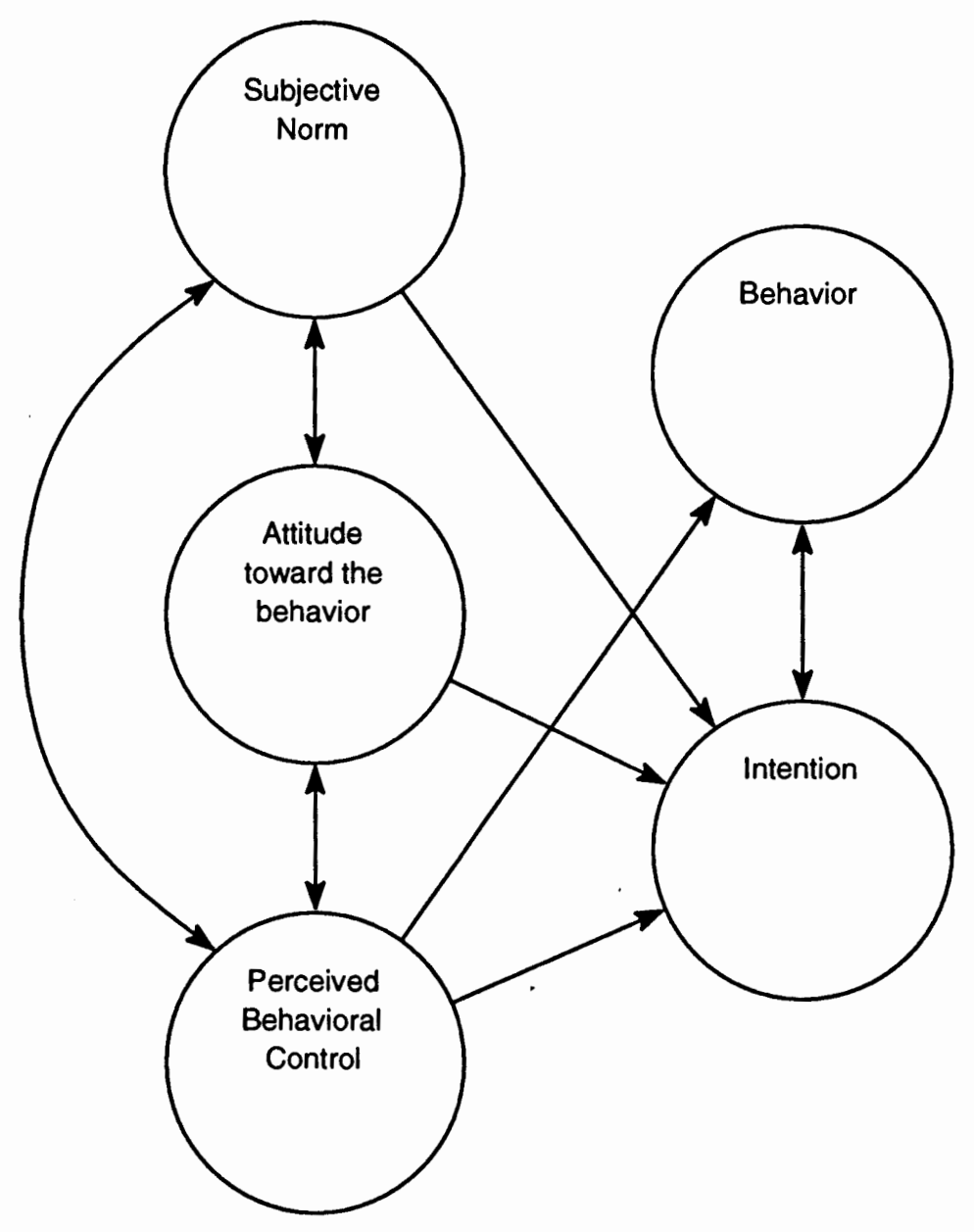

Figure 4. Ajzen's simultaneous model.

prediction of intention and behavior simultaneously from the antecedent variables. The second model (see Figure 5) examined the antecedent variables' ability to predict 
current behavior which then predicts intention. It was hypothesized that since recycling is so widely promoted as the politically correct behavior, subjective norms would be more predominant than attitude in determining behavior or intention within both of these models.

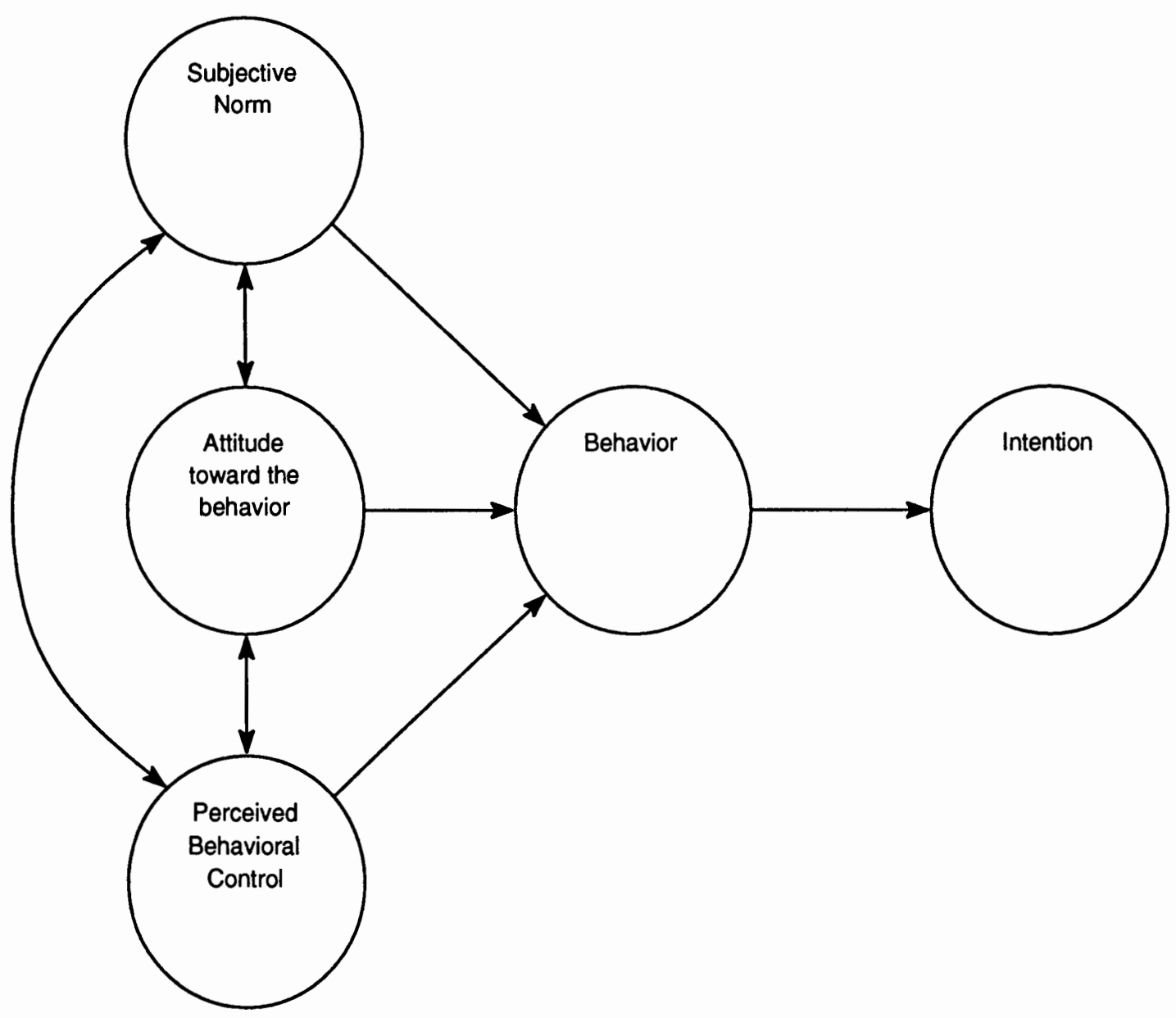

Figure 5. Variation of Ajzen's model.

Second, because recycling can be perceived as a commons dilemma, moral obligation values were examined to determine if self-and society-centered values are separate components 
of moral obligations. That is, did people clearly express separate self-centered values and society-values or is moral obligation a unidimensional concept?

Third, will incorporating moral obligation values and past behavior into the TPB model improve prediction of behavior and intentions? The role of past behavior in behavior prediction models has been contended. Moral obligation values is a probable factor as people may consider their own short-term self-interests vs. the longterm common good when intending to perform a recycling behavior. To investigate values and past behavior in the prediction of behavior and intention, a model using values and past behavior, along with Ajzen's model variables of SN, attitude and PBC as independent variables was examined (see Figure 6).

To investigate these factors that may influence recycling behaviors, door-to-door surveys were conducted. The survey instrument was designed to measure the constructs of self-reported recycling behavior, intentions, subjective norms, attitude, perceived behavioral control, past behavior, and moral obligation values. Randomly selected households in the tri-county metropolitan area were asked to complete the questionnaire. 


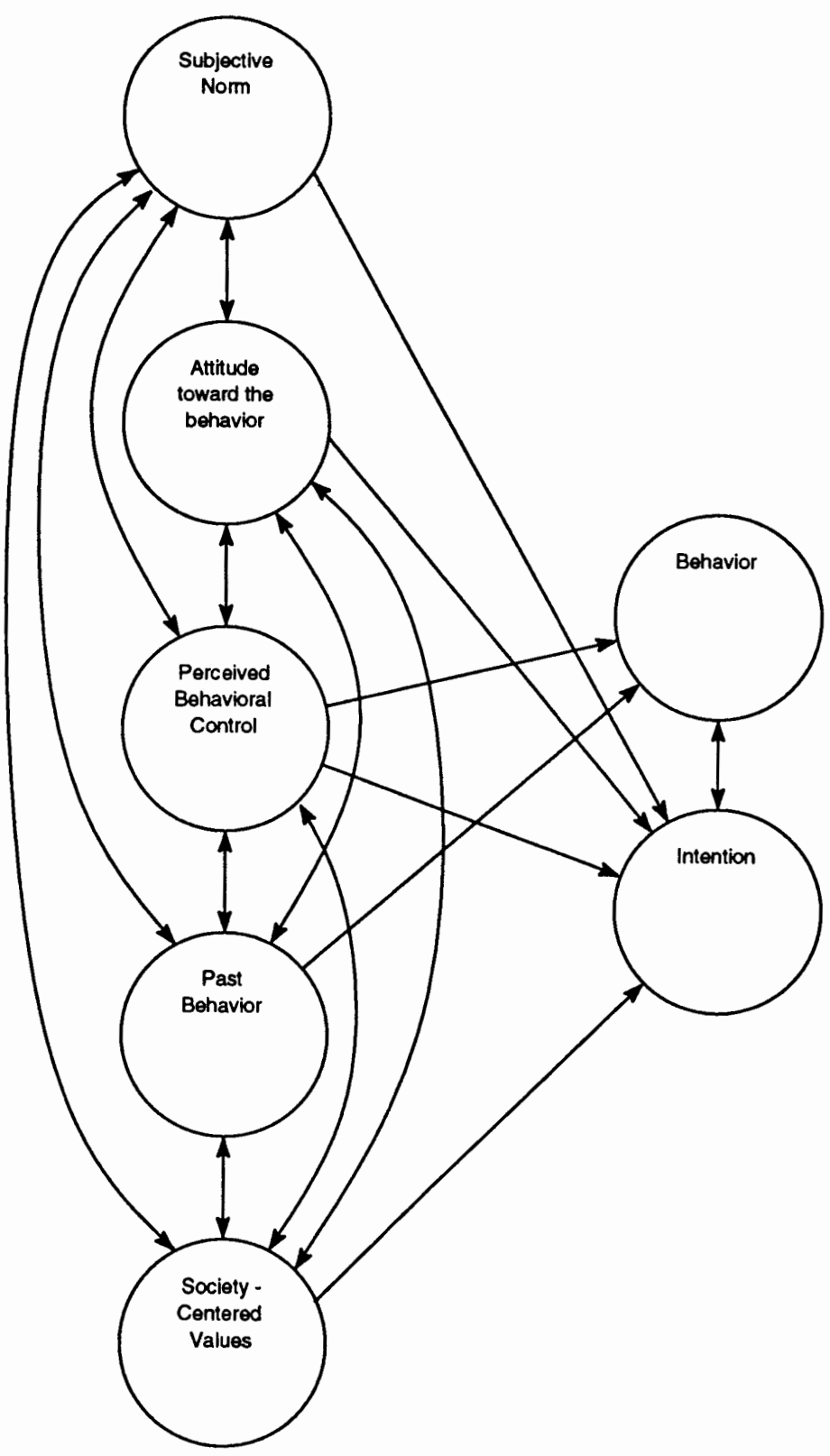

Figure 6. Simultaneous test of all variables. 
CHAPTER II

METHODS

SUBJECTS AND SAMPLING

Three hundred and forty-eight residents from the tricounty area (Clackamas, Multnomah, and Washington counties in Oregon) filled out the recycling survey. The tri-county area was chosen since all three counties are mandated by the state to have similar recycling services that collect the same types of materials.

A stratified sampling technique with probability proportionate to size was used in this study. First, the total tri-county region was broken into four areas, northeast, southeast, northwest, and southwest. The 1992 Cole's Directory, compiled on 1990 U.S. Census data, was used to determine population size and streets located in each zip code within an area. The percentage of the sample taken from each area was as follows: northeast, 248 , southeast, 33\%, northwest, $13 \%$, and southwest, $30 \%$.

The total population count for the tri-county area was 515,377. The target total sample size was 400. Therefore the target sample sizes were 96 for the northeast, 132 for the southeast, 52 for the northwest, and 120 for the southwest. 
A three-stage sampling procedure was used to select subjects. For each of the four areas, a zip code was randomly selected. Next, the last two digits in each consecutive number of a chart of random numbers was used to select a street from the alphabetical listing of streets within that zip code. If the street had a minimum of ten residences listed it was kept in the sample. If it had less than ten, the street was eliminated and a new zip code and street were drawn. If streets were located adjacent to each other, the most recently selected street was eliminated. This was repeated until sampling for each of the areas was complete. Houses to be surveyed were determined by locating the first street address listed within the zip code. This address was used as the starting point for surveying houses on the street. Households were approached until at least ten samples were collected in the neighborhood.

The researcher visited approximately 1,100 households', of which 354 agreed to participate in the survey, 234 refused, and the remaining 512 residents were not home. Of the 38 respondents who asked to mail the surveys in later, 84.28 (or 32 ) of the surveys were mailed back. Of the streets in the sample, only two were eliminated upon arrival, based on their location in a high crime and potentially dangerous area. All surveying was

${ }^{1}$ The total residences visited and the rejection rates are approximate since counts for these figures were not kept on the first five samples. 
done on the weekends to eliminate a potential bias of sampling only retired, unemployed or single income families.

\section{MATERIALS}

Community values and personal values, past behavior, attitudes, subjective norms, perceived behavioral control, intentions, and self-reported behaviors, along with some demographic information were assessed by questionnaire. (See Appendix for a copy of the survey.) Each of the eight constructs was measured or indicated by at least three questions.

Behavior measures were obtained by asking how often they have recycled newspaper, cardboard, aluminum, tin, glass, plastic, yard debris, magazines, household hazardous waste, (scrap, white,...) paper in the last month. The question "how often do you bring recyclables home from outings so that you can recycle them?" was asked as an additional measure of behavior. Each question had a 5-point answer continuum ranging from never to always. Since these were self-report measures, it would be more accurate to say that these were estimates or reports of the behavior and not actual measurements of the behavior.

Intention measures asked how likely it was that each of the items listed in the behavior measures would be recycled during the next month. Subjects were also asked how likely it is that they would bring home items from outings to be 
recycled. Response alternatives ranged from extremely unlikely (1) to extremely likely (5), with another category option of "Don't have any to recycle" or "No planned outings" available to respondents.

Attitude measures utilized a semantic differential of five bipolar adjective pairs. The statement "Cleaning, sorting and preparing materials for recycling is:" was followed by the five adjective pairs: harmful/beneficial, wise/foolish, unnecessary/necessary, thrifty/wasteful, and unimportant/important. A 7-point continuum was used for respondents' answers.

The construct subjective norms were measured using ten items. For all ten items, the respondents were asked about the extent to which they agree or disagree with the statement. Responses were indicated on a 6-point scale, ranging from strongly agree to strongly disagree. The first set of questions used the statement "My ... thinks I should recycle." The second set of questions used the statement "Generally speaking, I want to do what my ... thinks I should do when it comes to recycling." These statements were asked about the respondent's immediate family, neighbors, closest friends, environmentalists, and government officials.

Perceived behavioral control measures were obtained by asking three questions with a 7 point continuum with varying anchors. The first question addressed how much control 
people feel they have over whether they recycle every month. The second measure determined if they felt recycling paper, cans, and bottles every week is easy or hard. The third measure tapped their belief that they could prepare recyclables properly and get them out to be collected if desired.

Past behavior was measured by three separate questions asking respondents to compare their past and current levels of recycling. Subjects were asked to compare their present level of recycling to one month ago, six months ago, and one year ago. The response alternatives ranged from decreased greatly to increased greatly, on a 5-point scale.

The last set of items measured the moral obligation construct. The two components of moral obligation were measured using three statements with a 6-point scale ranging from strongly disagree to strongly agree. To measure society-centered values subjects were asked if they recycle because it helps preserve our limited natural resources for future generations, because recycling helps to save energy that would be needed to make brand new products, and because it helps to reduce the amount of garbage that goes into the community landfills. Self-centered values were measured by asking subjects if they recycle because they can receive money for some recyclable items, because recycling saves money on their garbage bill, and because it makes them feel good. 
PROCEDURE

The researcher visited each residence on the street. After introducing herself, she briefly described the nature and goal of the study. In order to lessen the chances of bias in the respondents' answers, potential respondents were told that the goal of the study was to look at the differences between recyclers and non-recyclers. If the respondent agreed to participate, they were handed the form and asked to fill it out. The researcher volunteered to come back to pick it up in approximately a half an hour, after having talked with other people in the neighborhood. If the resident answered that it was not a good time, they were offered a self-addressed stamped envelope to return the completed survey by a specific date. 
CHAPTER III

ANALYSIS

SUBJECTS

A total of 35 neighborhoods were surveyed. Of the 348 surveys collected, only 303 cases were used in the analysis. The other 45 surveys were eliminated because less than $50 \%$ of the questions for at least one of the eight constructs were answered.

\section{ANALYSIS OVERVIEW}

In coding the responses for the intention construct, all "Don't have any to recycle" and "No outings planned" responses were recoded to extremely unlikely. This recoding was necessary because there was not a matching category for the behavior construct items. The rationale for the change was that if people do not even recognize that they have these very prevalent items, they will not recycle the materials.

Two of the survey questions were dropped from the analysis due to the high levels of missing responses. These two questions were measures of subjective norms asking about neighbors. Of the 303 surveys, $14.5 \%$, or 44 of the respondents failed to answer the first neighbor question and 
7.6\% (or 23) failed to answer the second neighbor question. All "Other" questions (from the behavior and intentions sections of the questionnaire) were not used in the analysis.

\section{Step 1: Moral Obligation}

Confirmatory factor analysis was performed on the moral obligation variables to determine if the two factors of self-and society-centered values were distinct, as hypothesized.

\section{Step 2: Subjective Norms}

Exploratory factor analysis was performed on the subjective norms variables. This was conducted to determine if the items would combine into a smaller number of logical groupings.

\section{Step 3: Grouping for Intentions and Behaviors}

The method for collapsing the indicators of intentions and behavior was based on expert knowledge and tested in this stage of the analysis. The proposed grouping placed the ten recyclable items (or materials) into categories representing the degree of difficulty a resident would encounter in trying to recycle the item. Based on the fact that all residents have certain items picked up in their curbside service, other items can be recycled at only a few depots or stores on certain dates, and some items are easier to prepare and handle than others, three categories (easy, 
medium, and hard) of recycling items were created. The easy category contained the items newspaper, cardboard and glass because they are the easiest and most common materials to clean and/or handle. The medium category contained aluminum, tin and magazines because it takes more work to handle them. Some aluminum cans may be taken to a store while other aluminum usually has to be cleaned. Tin cans have to be cleaned and the ends need to be cut out. Magazines can be recycled at curbside in some areas, others have to haul them to a depot. Magazines are heavy and sometimes hard to carry. The hard category contained the items plastics, household hazardous wastes, scrap paper and yard debris. Plastics, household hazardous wastes and scrap paper are harder to recycle since they are not collected curbside and there are few places, with limited hours, that accept them. Yard debris was placed in this category, since it is not always picked up curbside. (Yard debris recycling is relatively new. Some residents have had the service for almost a year, some residents have access to weekend depots.) These categories were used to collapse both the behavior and intention variables. To substantiate the creation of these categories, an exploratory factor analysis was done using the ten variables that indicated whether or not the respondent's recycling service accepted each of the items. 
Step 4: Measurement Model

Confirmatory factor analysis, was conducted on the 258 observations that were complete for all measures to simultaneously test the goodness-of-fit of the measured variables and the eight latent constructs. Variables found in the measurement model to have high error terms or nonsignificant $t$-values were eliminated. The eight constructs and their associated measured variables are illustrated in Figure 7.

\section{Step 5: Ajzen's Models}

Once the measurement model had been modified, structural equation analyses were performed on the variations of Ajzen's Theory of Planned Behavior model. The first analysis included both the intentions and behavior latent variables simultaneously in the model. (See Figure 7 for this model).

In the second analysis, the behavior and intention variables were reversed from their pattern of influence as hypothesized by Ajzen. As previously mentioned, the behavior questions in this study measured what the respondent had done in the last month's time, while the intention questions asked what the respondent planned to do in the upcoming month. Therefore, a model in which recent behavior was used to predict future intentions also was tested. (See Figure 5). 

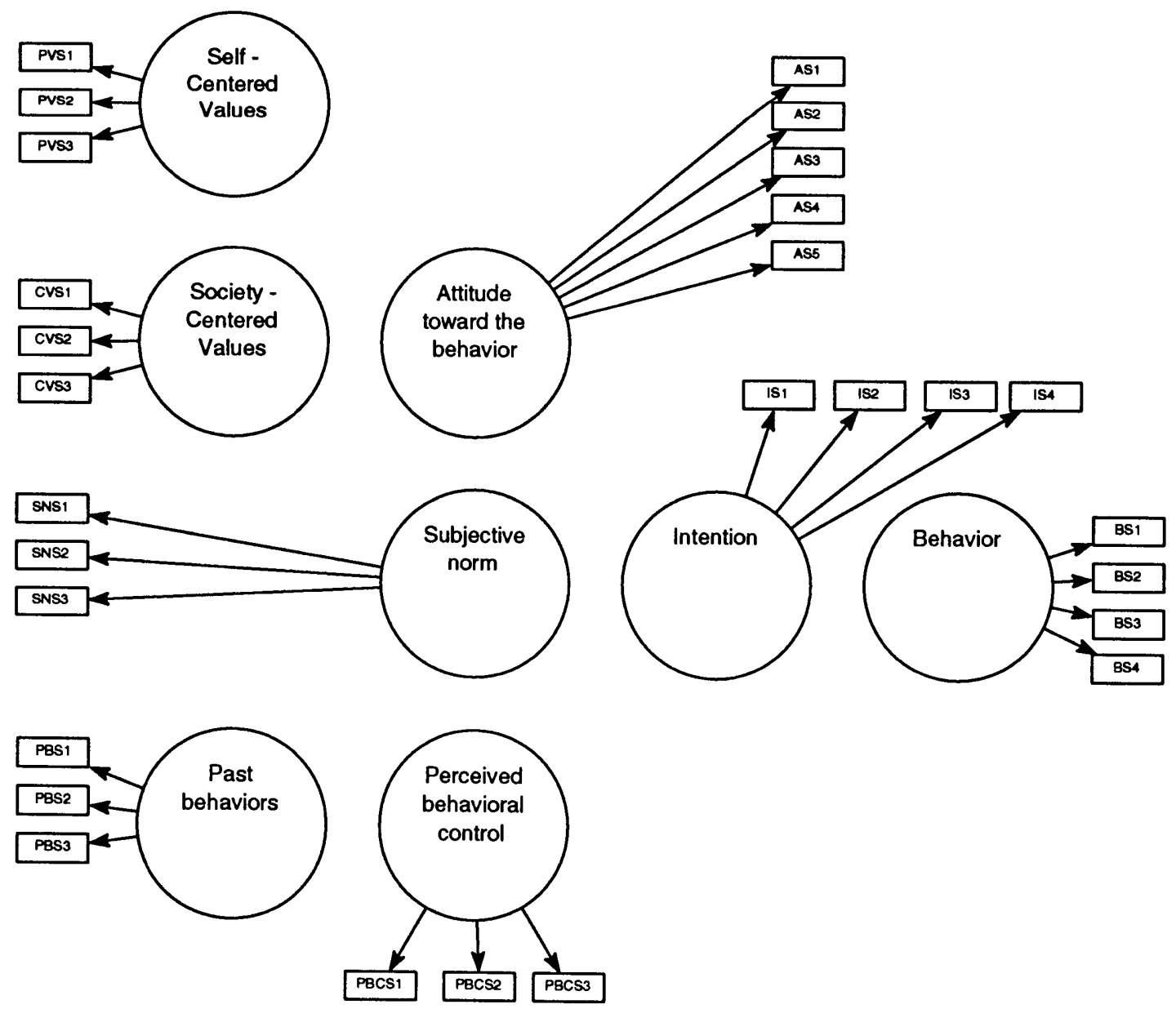

Figure 7. Latent constructs and their associated measured variables.

\section{Step 6: Expanded Models}

To determine what influence, if any, moral obligation values and past behavior had on intentions and behavior, a structural equation analysis with societal-centered values, past behavior, attitude, subjective norm, and perceived behavioral control specified as having a direct effect on the dependent variables of intention and behavior was conducted (See Figure 6). 
In addition, a structural equation analysis estimated a more elaborate model theorized by the investigator. Two versions of the model, one with behavior influencing intentions and one with intentions and behaviors simultaneously in the model were estimated (see Figures 8 and 9, respectively, for these models). These models incorporated all hypothesized paths from the earlier models and included the hypothesized paths between the societycentered variable and SN, attitude and intentions.

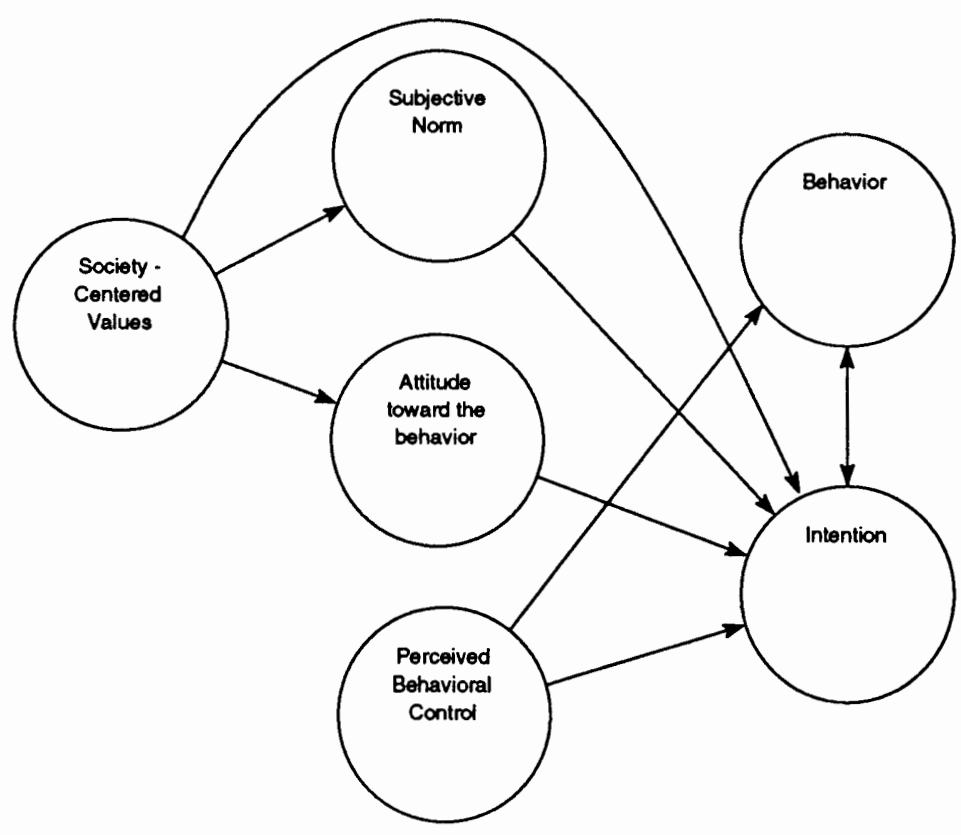

Figure 8. Expanded simultaneous model. 


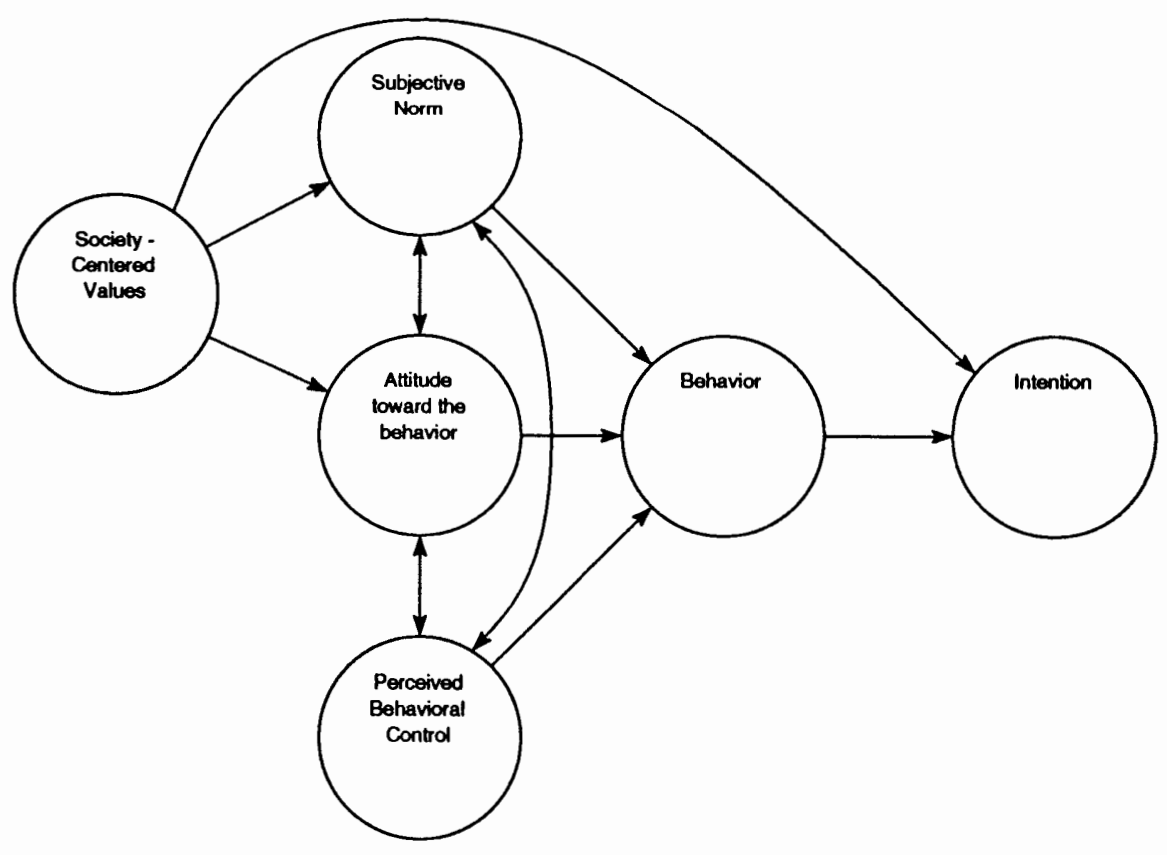

Figure 9. The expanded variation model.

\section{ASSESSMENT OF GOODNESS-OF-FIT}

To assess the overall fit of the model, four indices were examined. First was the chi-square test of the null hypothesis that the model fits the data. However, this test is extremely sensitive to sample size and often too powerful, therefore, other descriptive measures of fit were used as well (Bentler \& Bonett, 1980). The Adjusted Goodness of Fit Index (AGFI) is a measure of the relative amount of variances and covariances accounted for by the model. It is less dependent on sample size than the chisquare and incorporates a penalty function for adding parameters. The Parsimonious Goodness of Fit Index (PGFI), was also calculated for each model (Mulaik et al, 1989). 
This was used to compare models that differ in the number of variables. Both the AGFI and the PGFI vary between 0 and 1 with higher values indicating better fit of the model. The root mean square residual reflects the average residual between the observed data and the model generated data in terms of correlations (or covariances). Root mean square residuals would be small if the model fits well.

Two measures of detailed fit, modification indices and t-values, were examined for all models. These tested specific parameters of the model as opposed to the overall fit of the model. Modification indices indicated when a particular parameter not estimated by the model could improve the fit if that parameter was included in the model. The t-value for a parameter tested whether the sample parameter was significantly greater than zero. In other words, it tested if the path, factor loading or covariance contributes significantly to the model. All models were modified by adding or omitting paths based on theorical reasoning, t-values and modification indices. 
CHAPTER IV

RESULTS

DESCRIPTIVE STATISTICS

The typical (modal) respondent's household utilized their curbside service and recycled at home. They lived in a single family home that they owned. There were two adults with no children (under the age of 18) living in the residence. Table I gives a more detailed description of the entire sample.

Almost all households ( $95.7 \%$ ) reported having curbside recycling service available to them. This figure would be expected in the metropolitan area, since all the local governments are required to have such service available to all residents. The few respondents who claimed not to have recycling service may haul their own garbage to the dump. Sixty-five percent of the respondents noted that they also used a recycling depot. Only $21.8 \%$ took recyclable materials to a buyback center. Forty and six-tenths percent gave recyclables to non-profit groups (e.g. Boy Scouts, etc.). Only 4.68 of the sample claimed they didn't know what recycling services were available to them; one respondent claimed that no recycling services were available. 
For the ten recyclable materials listed as items, $97 \%$ of the sample said they could recycle newspaper, $77.6 \%$ said they could recycle aluminum, $85.5 \%$ said they could recycle

TABLE I

DESCRIPTION OF SAMPLE, IN PERCENTAGES

\begin{tabular}{|c|c|c|c|c|c|c|}
\hline $\begin{array}{l}\text { Recycle at } \\
\text { home }\end{array}$ & $\begin{array}{l}97.68 \\
\text { yes }\end{array}$ & $\begin{array}{l}2.4 \% \\
\text { no }\end{array}$ & & & & \\
\hline $\begin{array}{l}\text { Own or } \\
\text { Rent }\end{array}$ & $\begin{array}{l}83.78 \\
\text { own }\end{array}$ & $\begin{array}{l}16.8 \% \\
\text { rent }\end{array}$ & & & & \\
\hline $\begin{array}{l}\text { Type of } \\
\text { home }\end{array}$ & $\begin{array}{l}88.18 \\
\text { single }\end{array}$ & $\begin{array}{l}7.6 \% \\
\text { apt./ } \\
\text { duplex }\end{array}$ & $\begin{array}{l}5.2 \% \\
\text { other }\end{array}$ & & & \\
\hline $\begin{array}{l}\text { No. of } \\
\text { persons }\end{array}$ & $\begin{array}{l}8.6 \% \\
\text { one }\end{array}$ & $\begin{array}{l}29.48 \\
\text { two }\end{array}$ & $\begin{array}{l}22.18 \\
\text { three }\end{array}$ & $\begin{array}{l}23.4 \% \\
\text { four }\end{array}$ & $\begin{array}{l}9.2 \% \\
\text { five }\end{array}$ & $\begin{array}{l}6.28 \\
6-11\end{array}$ \\
\hline $\begin{array}{l}\text { No. of } \\
\text { children }\end{array}$ & $\begin{array}{l}48.58 \\
\text { zero }\end{array}$ & $\begin{array}{l}16.5 \% \\
\text { one }\end{array}$ & $\begin{array}{l}21.5 \% \\
\text { two }\end{array}$ & $\begin{array}{l}8.68 \\
\text { three }\end{array}$ & $\begin{array}{l}2.0 \% \\
\text { four }\end{array}$ & $\begin{array}{l}1.98 \\
5-9\end{array}$ \\
\hline
\end{tabular}

tin, $93.7 \%$ said they could recycle glass, $68 \%$ said they could recycle magazines, $68 \%$ said they could recycle plastic, $89.1 \%$ said they could recycle cardboard, $66.3 \%$ said they could recycle yard debris, $37.6 \%$ said they could recycle household hazardous waste, and $39.3 \%$ responded that they could recycle paper (white, scrap, etc). 


\section{STEPS OF THE ANALYSIS}

Step 1: Factor analysis of moral obligation

The confirmatory factor analysis using LISREL suggested that the item "I recycle because I can receive money" should be dropped. The pattern of the standardized residuals, low variance accounted for and a large modification index demonstrated that the variable was not a good measure of self-centered values. The modification index for the item "I recycle because it makes me feel good" indicated that the question should load on the society-centered values factor so it was moved to that factor. The final model for moral obligation had the four items about preserving natural resources, saving energy, reducing amounts going into community landfills and making me feel good as measures for the first factor. It appears that intrinsic satisfaction is related to doing the right thing to save resources and the environment. The second factor had retained only one measure, "I recycle because it saves on the garbage bill." The chi-square for the final model, with 6 degrees of freedom, was $12.32(\mathrm{p}=0.055)$, the AGFI $=0.955$ and the root mean square residual was 0.135 . See Table II for the standardized factor loadings.

Step 2: Factor analysis of subjective norms

The principle components analysis of the subjective norms items found three factors with eigenvalues greater than one. Oblimin rotation of the three factors extracted 
with the principle axis factoring revealed a complex factor loading pattern. (See Table III for the rotated factor loadings.) The first factor reflected a measure of how much the respondent wanted to do what others want them to do.

TABLE II

THE STANDARDIZED FACTOR LOADINGS FOR CONFIRMATORY FACTOR ANALYSIS OF THE MORAL OBLIGATION VARIABLE

\begin{tabular}{lll}
\hline Category & Factor 1 & Factor 2 \\
\hline Future Resources & 1.000 & 0.000 \\
Saves Energy & 0.836 & 0.000 \\
Save Landfill Space & 0.711 & 0.000 \\
Feels Good & 0.717 & 0.000 \\
Reduces Garbage Bill & 0.000 & 1.000 \\
\hline
\end{tabular}

This factor accounted for the most variance of the three factors $(42 \%$ of the total $62.1 \%$ of the variance accounted for by the three factors). The second factor reflected the impact of those persons most immediate or closest to the respondent (family and close friends). It accounted for $11 \%$ of the variance. The third factor, responsible for only $9.1 \%$ of the accounted variance, reflects a measure of beliefs about what important or knowledgeable people may think about recycling. The lower portion of Table III presents the percentage of both unique and common and unique 
variance accounted for by each factor. Bold numbers indicate the factor loadings which were considered to be high on a particular factor.

TABLE III

ROTATED PATTERN FACTOR MATRIX FOR SUBJCECTIVE NORMS AND PERCENTAGES OF ACCOUNTED VARIANCE

\begin{tabular}{|c|c|c|c|}
\hline Category & Factor 1 & Factor 2 & Factor 3 \\
\hline TT Immediate Family & -0.056 & 0.922 & -0.005 \\
\hline TT Close Friends & 0.120 & 0.572 & 0.118 \\
\hline TT Environmentalists & -0.007 & 0.203 & 0.381 \\
\hline TT Government officials & 0.041 & -0.098 & 0.982 \\
\hline WT Immediate Family & 0.317 & 0.423 & 0.037 \\
\hline WT Close Friends & 0.682 & 0.187 & -0.049 \\
\hline WT Environmentalists & 0.790 & 0.056 & -0.049 \\
\hline WT Government officials & 0.926 & -0.188 & 0.160 \\
\hline \& Accounted Variance & & & \\
\hline$q$ of Unique & 41.57 & 29.77 & 23.23 \\
\hline 8 of Common and Unique & 57.41 & 44.86 & 38.42 \\
\hline
\end{tabular}


Three new factors to measure Subjective Norms were created based upon the results of the exploratory factor analysis. The first factor, 'Want to', was the mean of the scores for the variables that measured how much the respondent "wanted to do what her/his" closest friends, environmentalists, and government officials thought s/he should do when it comes to recycling. The second new factor, "Important", was the mean of the scores for three of the variables that measured how much the respondents believed that their immediate family and closest friends thought they should recycle, and how much the respondents wanted to do what their immediate family thought they should do. The third new factor, "They think", was the mean of the scores measuring what the respondents believed that environmentalists and government officials thought they should do with regard to recycling. These groupings could represent the respondents' motivation to recycle because it is promoted to be a correct behavior (factor 1), perceptions of what their closest reference groups think and the desire to do what their family wants (factor 2) and perceptions of what experts think (factor 3 ). It is interesting to note that perceptions of what family and friends think are distinct from what experts think. Although these factors are correlated $(r=0.348)$, perceptions of what family and friends think is not always in agreement with what experts think. A similar pattern can be seen with respect to what 
people want to do. If a person's immediate family thinks they should recycle they tend to want to recycle and vice versa. However, what the experts think and wanting to do what they think loads on separate factors, which implies this relationship is not as strong. Factor 3 and factor 1 are correlated at 0.436 suggesting that people would not necessarily want to recycle just because they know that experts think they should recycle.

Step 3: Factor analysis to test the groups for behavior and intentions

Exploratory factor analysis of the variables describing which items the respondent had included in their recycling service agreed with the categories devised based on expert knowledge. Principle components analysis found two factors with eigenvalues greater than one and a third factor with an eigenvalue of 0.97. Principle axis factoring with the three factors accounted for $38.9 \%$ of the variance. See Table IV for factor loadings.

The first factor had high loadings for newspaper, glass and cardboard. The second factor had high loadings for household hazardous waste, paper, plastic, and yard debris. The third factor had high loadings for aluminum, tin, and magazines. These factors agreed with the categorization based on information that all residents would have newspaper, glass, and cardboard picked up in their curbside service, (easy behavior); aluminum, tin, and magazines 
(medium behavior) may be picked up curbside and require a bit more work to recycle. The hard behavior category had plastics, (scrap, white,...) paper, household hazardous waste and yard debris, which are not normally picked up at curbside. This analysis lends support to the groupings for the behavior and intentions variables.

TABLE IV

ROTATED PATTERN FACTOR MATRIX FOR RECYCLABLE ITEMS

\begin{tabular}{|c|c|c|c|}
\hline Material & Factor 1 & Factor 2 & Factor 3 \\
\hline Newspaper--E & 0.588 & 0.022 & -0.024 \\
\hline Aluminum--M & 0.089 & 0.057 & -0.548 \\
\hline Tin--M & 0.424 & -0.089 & -0.483 \\
\hline Glass--E & 0.782 & -0.058 & -0.082 \\
\hline Magazines--M & 0.030 & 0.345 & -0.375 \\
\hline Plastic- $-\mathrm{H}$ & -0.010 & 0.490 & -0.032 \\
\hline Cardboard--E & 0.519 & 0.210 & -0.024 \\
\hline Yard Debris--H & 0.218 & 0.383 & -0.037 \\
\hline H. H. Haz. Waste--H & 0.069 & 0.582 & 0.080 \\
\hline Paper--H & -0.151 & 0.534 & -0.241 \\
\hline
\end{tabular}


Step 4: Test of the Measurement Model

The confirmatory factor analysis using LISREL was conducted for the 28 measures of the eight constructs. A11 the measured variables were specified to load on only one factor, correlations among the eight constructs were estimated and the errors of the 28 measured variables were assumed to be uncorrelated. Table V gives the standardized factor loadings for the final measurement model. The results of the initial analysis indicated that two of the measured variables, both variables for the self-centered moral obligation construct, should be dropped from the model because of negative or greater than one error terms in the model. Both variables ("the reason I recycle is because I can receive money" and "the reason I recycle is because it saves me money on my garbage bil1") accounted for very little, if any, variance in the model, and had nonsignificant $t$-values for the associated factor loadings. This analysis reinforced the results of the factor analysis on moral obligations in step 1, which also dropped the variable "I recycle because I can receive money." Dropping this and the garbage bill item required eliminating the personal values construct as this question was the only indicator of the construct. All other variables had significant $t$-values associated with the loadings on their construct. 
The calculated measures of fit for the final

measurement model (chi-square value 653.21 with df $=278 \mathrm{p}<$ $.000)$ indicated that the model could be rejected. However, the AGFI of 0.803 indicated that the data were being fairly well described by the model. The small root mean square

\section{TABLE V}

LAMBDA X MATRIX WITH THE FINAL VALUES OF THE FACTOR LOADINGS FOR THE MEASUREMENT MODEL

\begin{tabular}{|c|c|c|c|c|c|c|c|}
\hline & $\mathrm{BEH}$ & INT & $\mathrm{SN}$ & ATT & $\mathrm{PBC}$ & $\mathrm{PB}$ & COMMO \\
\hline BHARD & .681 & & & & & & \\
\hline BEASY & .757 & & & & & & \\
\hline BMED & .805 & & & & & & \\
\hline BHOME & .510 & & & & & & \\
\hline IHARD & & .691 & & & & & \\
\hline IEASY & & .751 & & & & & \\
\hline IMED & & .862 & & & & & \\
\hline IHOME & & .450 & & & & & \\
\hline WANTO & & & .617 & & & & \\
\hline IMPORT & & & .800 & & & & \\
\hline THEYT & & & .502 & & & & \\
\hline HARM / BEN & & & & .766 & & & \\
\hline WISE/FOO & & & & -.540 & & & \\
\hline NEC / UNNE & & & & .930 & & & \\
\hline THRIFT/W & & & & -.590 & & & \\
\hline UNIMP / IM & & & & .941 & & & \\
\hline CONTROL & & & & & .461 & & \\
\hline EASY & & & & & .754 & & \\
\hline AGREE & & & & & .644 & & \\
\hline 1MONTH & & & & & & .466 & \\
\hline 6MONTH & & & & & & .918 & \\
\hline 1YEAR & & & & & & .710 & \\
\hline FUTURE & & & & & & & .798 \\
\hline ENERGY & & & & & & & .763 \\
\hline LANDFILL & & & & & & & .679 \\
\hline FEELS & & & & & & & .644 \\
\hline
\end{tabular}


residual for the model, $\mathrm{RMS}=0.059$, also indicated a well fitting model, as did the high PGFI (0.938).

As can be seen in Table VI, correlations among the eight latent variables showed a high correlation between the behavior and intention variables. The remaining correlations were low, supporting the discriminant validity of all other constructs.

TABLE VI

CORRELATION AMONG LATENT VARIABLES

\begin{tabular}{|c|c|c|c|c|c|c|c|}
\hline & $\mathrm{BEH}$ & INT & $\mathrm{SN}$ & $\mathrm{ATT}$ & PBC & PB & $\mathrm{CV}$ \\
\hline $\mathrm{BEH}$ & 1.00 & & & & & & \\
\hline INT & 0.912 & 1.00 & & & & & \\
\hline SN & 0.359 & 0.454 & 1.00 & & & & \\
\hline ATT & 0.365 & 0.306 & 0.519 & 1.00 & & & \\
\hline PBC & -0.524 & -0.387 & -0.276 & -0.416 & 1.00 & & \\
\hline $\mathrm{PB}$ & -0.028 & 0.081 & 0.091 & -0.071 & -0.038 & 1.00 & \\
\hline $\mathrm{CV}$ & 0.459 & 0.335 & 0.420 & 0.551 & -0.452 & -0.014 & 1.00 \\
\hline
\end{tabular}

TEST OF THE STRUCTURAL MODELS

Structural equation analysis was performed to test the two variations of Ajzen's model of Planned Behavior, a model with the five independent variables simultaneously predicting the two dependent variables (intention and behavior) and the two variations of the hypothesized model. 
Table 7 shows the chi-square and the goodness-of-fit values for all models tested. LISREL was used for all analyses. Step 5: Ajzen's Models

The covariance structure analyses did not confirm the Figure 4 variation of Ajzen's model in which behaviors and intentions were specified as being correlated. Figure 10 presents the final model after all non-significant paths

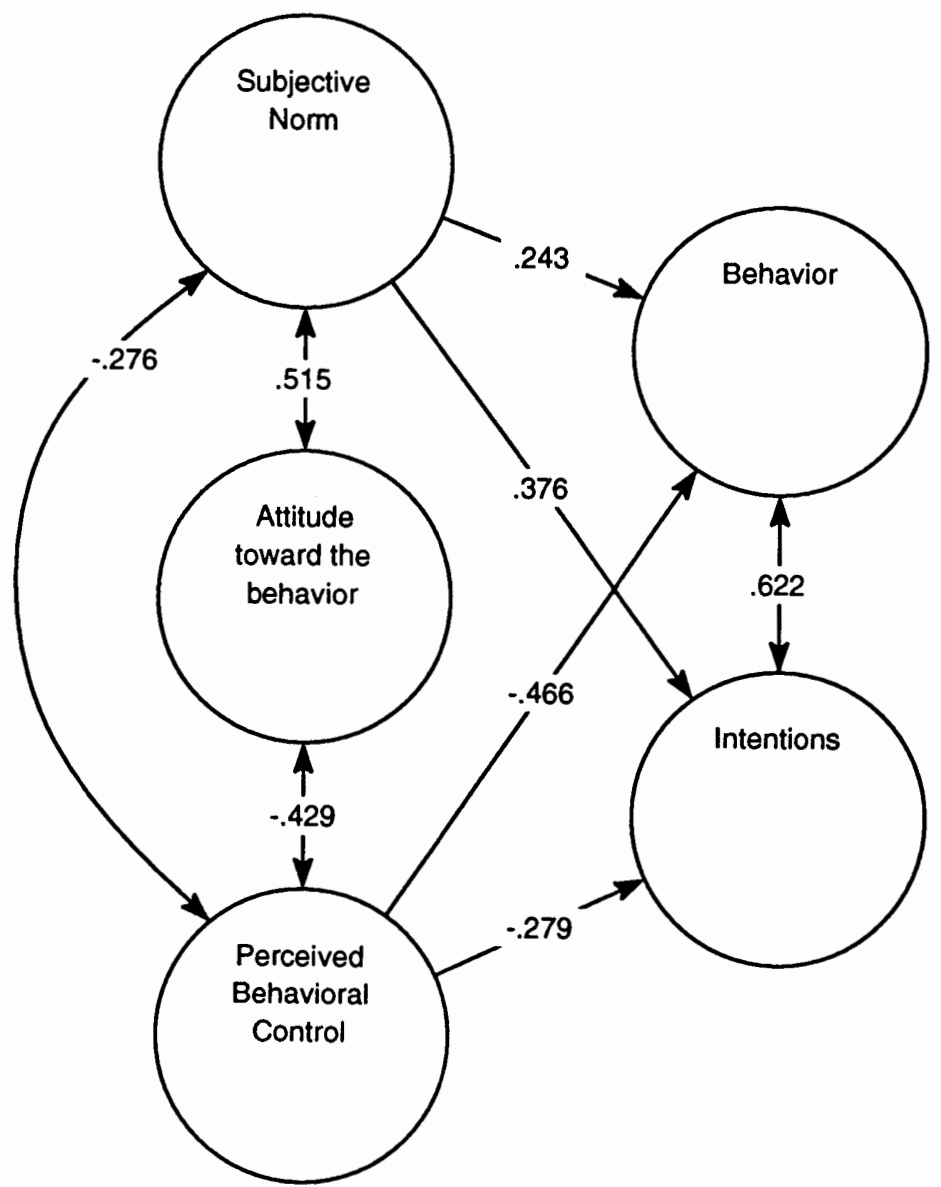

Figure 10. Standardized path coefficients and correlations of final Ajzen's simultaneous model.

were removed and a new path was added. The standardized 
path coefficients and correlations are given for each significant path. In this model, attitude did not directly influence any of the dependent variables. However, attitude was correlated with subjective norms (0.515) and with perceived behavioral control $(-0.429)$. These correlations were very stable across all other models tested in this study .

A path was added from subjective norms to behavior. In this model, subjective norms had a greater influence upon intentions than behavior and perceived behavioral control had the greatest influence upon behavior. This pattern of results appears to support one of the hypotheses of this study, the influence of subjective norms was more predominant than the influence of attitudes on intentions and behavior.

It should be noted that low scores on the perceived behavioral control items reflected a higher degree of perceived control. Therefore, a negative relationship with this variable would indicate that as levels of the other variables increased, so did levels of perceived behavioral control.

Next, the structural equation analysis was performed on the Figure 5 version of Ajzen's model with the behavior variable influencing intention. Once again, the results did not confirm Ajzen's theory and are very similar to the simultaneous version. Attitudes did not influence either 
behaviors or intentions. Perceived behavioral control had a stronger influence $(-.408)$ than subjective norms (.308) upon behavior. The behavior variable mediated the effects of the independent variables upon intention as no independent variable had a direct effect on intentions. Figure 11 presents the final model with the significant standardized path coefficients.

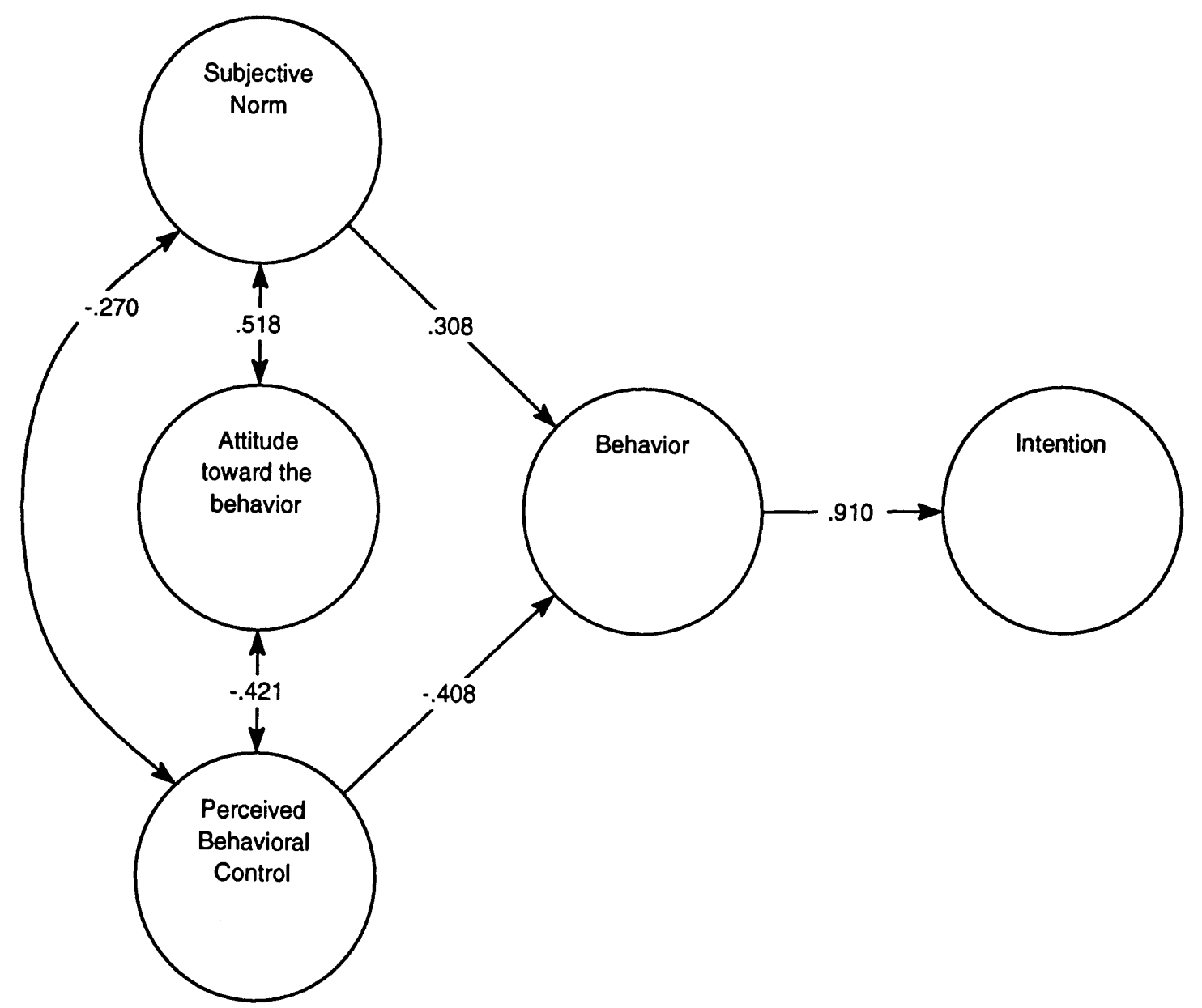

Figure 11. Standardized path coefficients and correlations of the final variation of Ajzen's model. 
As can be seen in Table VII, the fit of these models were very similar. The second model fit slightly better after adjusting for differences in degrees of freedom as the PGFI was 0.642 for this model and 0.630 for the simultaneous model.

Step 6: Expanded models

The Figure 6 model with subjective norms, attitude, perceived behavioral control, past behavior, and societycentered values as the independent variables influencing intention and behavior was tested. Figure 12 presents the final model. The analysis found that subjective norms influenced only intentions, perceived behavioral control influenced intention and behavior, and society-centered values influenced only behavior. Neither attitude nor past behavior had a significant relationship with either dependent variable. This model determined that one of the new variables, society-centered values, had a significant relationship with behavior. Therefore, incorporating this variable into Ajzen's model could improve the fit of the model. 


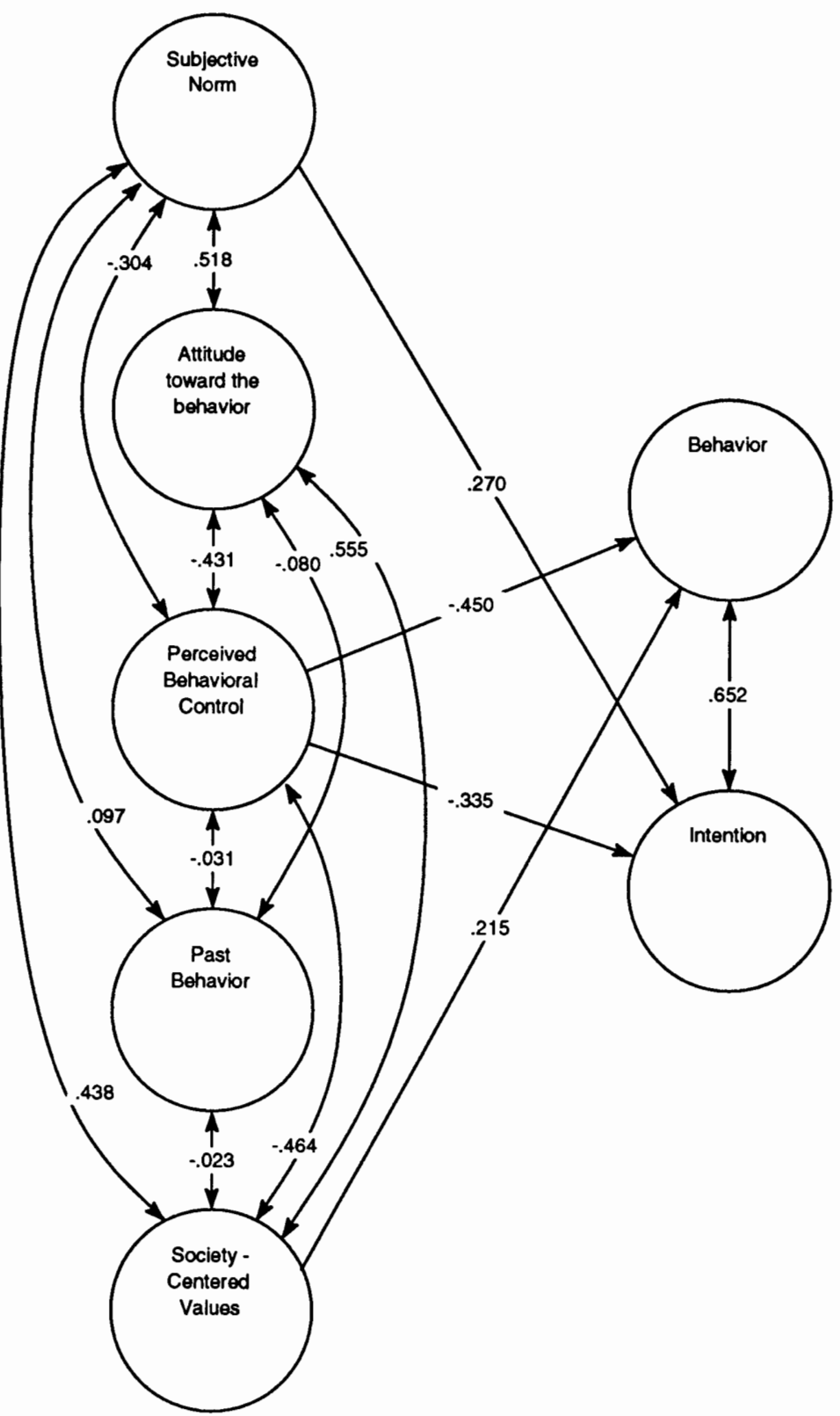

Figure 12. Standardized path coefficients and correlations of the simultaneous test. 
TABLE VII

CHI-SQUARES, DEGREES OF FREEDOM, AGFI, PGFI AND RMS FOR MODELS TESTED

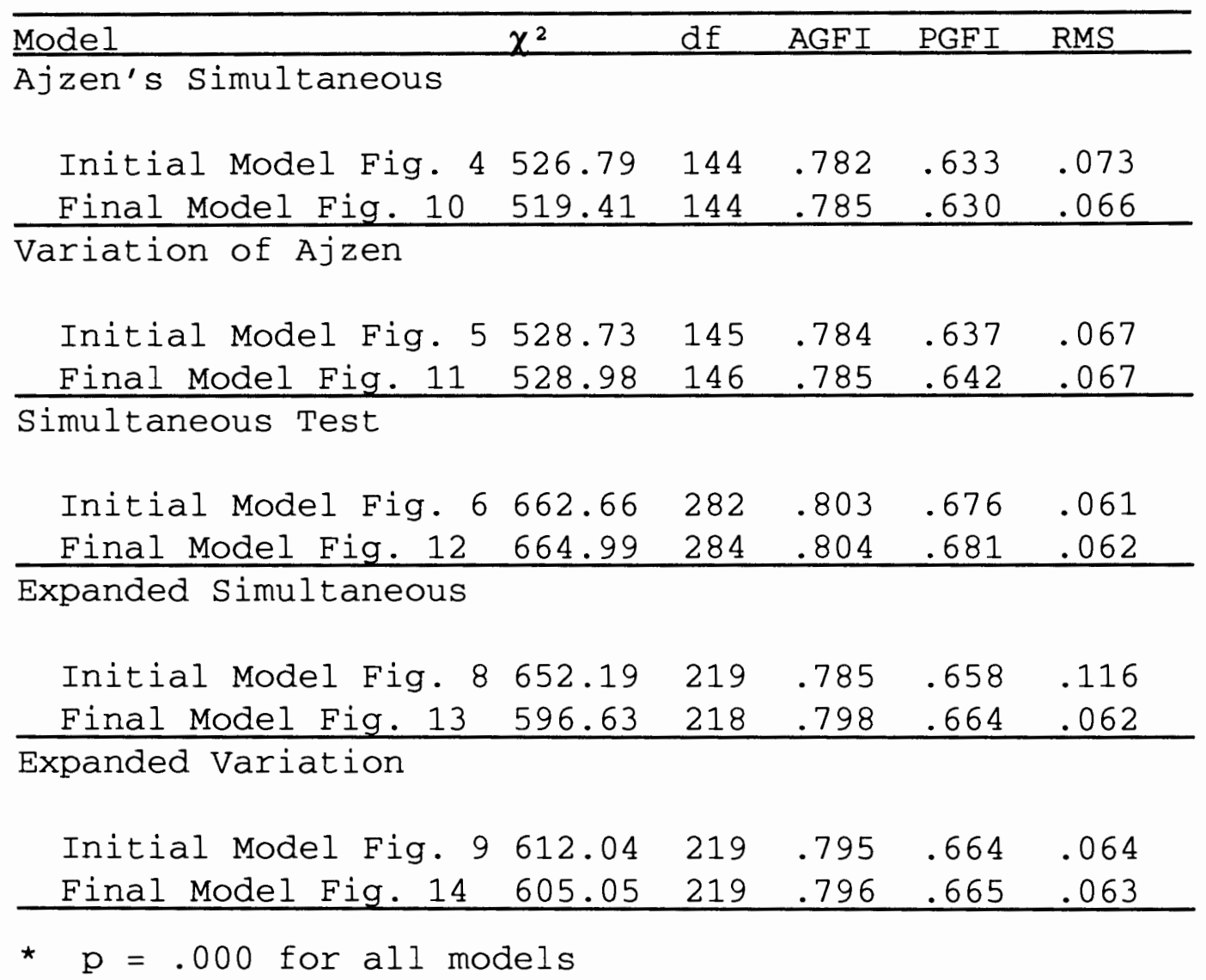

To further investigate the role of society-centered values and past behaviors, two additional models were tested. The first contained both intentions and behavior as correlated dependent variables in the model (Figure 8). In the second model, behavior influenced intentions (Figure 9). It was hypothesized that society-centered values affected subjective norms and attitudes and that past behaviors influenced perceived behavioral control. The results of the analysis found that in both models, past behavior did not 
significantly influence any other variable in the model and so was dropped from further analysis. In both models, the hypothesized path from society-centered values to intentions was not significant and so was eliminated. However instead, a new path from society-centered values to behavior was suggested by a large modification index and found to be significant. The paths from society-centered values to attitude and subjective norms were significant and the analyses also suggested a path between society-centered values and perceived behavioral control that had not been hypothesized. Figures 13 and 14 show the standardized path coefficients and correlations of the final versions of these two models. The addition of society-centered values improved predictions over Ajzen's models (PGFI of 0.665 vs. 0.642 , respectively). See Table VII for chi-squares and measures of fit of all models. When the standardized solutions of the simultaneous model were examined, the largest influence on intention was subjective norms. Of the three variables influencing behavior, perceived behavioral control was the greatest and subjective norms and societycentered values were approximately the same $(0.181$ and 0.171 , respectively). Society-centered values directly influenced behavior, subjective norms, attitudes and 


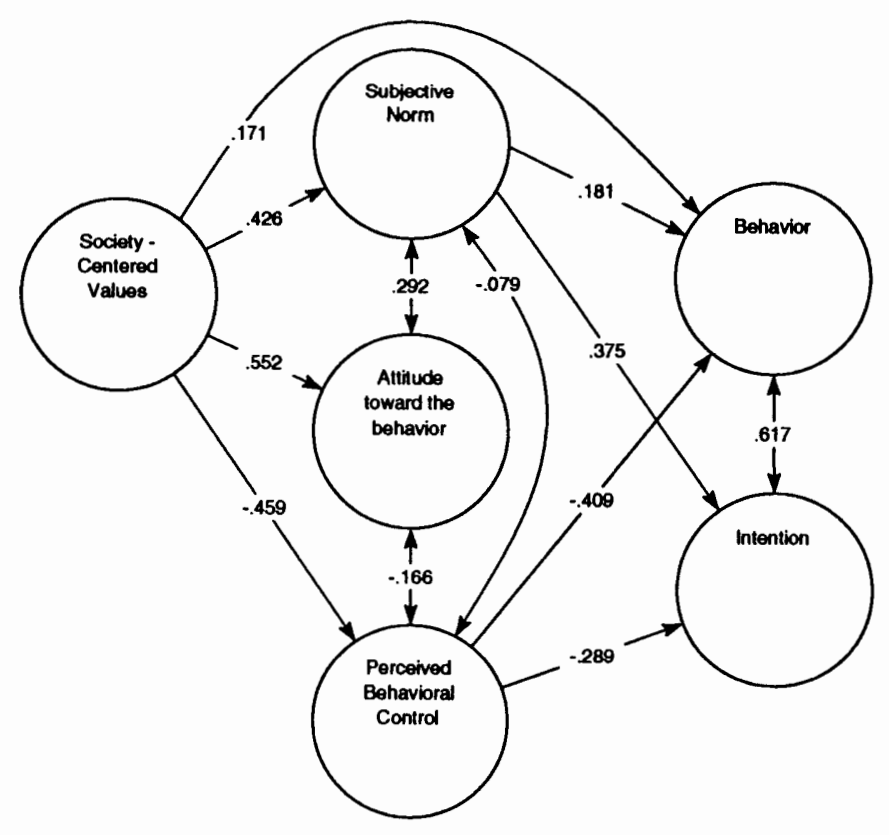

Figure 13. Standardized path coefficients and correlations of the expanded simultaneous model.

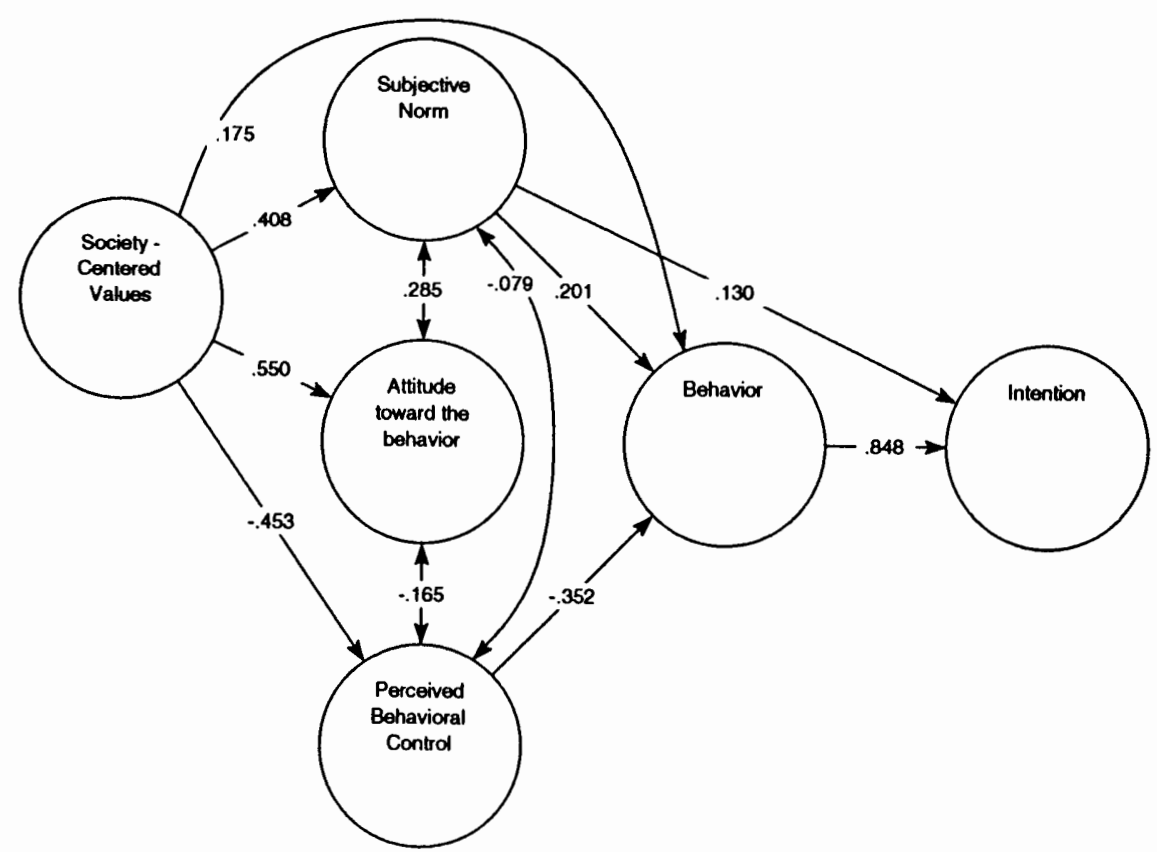

Eigure 14. Standardized path coefficients and correlations of the expanded variation model. 
perceived behavioral control. The influence of societycentered values was quite strong for subjective norms, attitudes and perceived behavioral control. There was a similar pattern of results for the expanded variation model (Figure 14). Society-centered values influenced the same variables as in the simultaneous model. Of the three variables influencing behavior, perceived behavioral control was the strongest, subjective norms was next and societycentered values was weakest. In this model, the latent variable intentions was directly influenced only by behavior and subjective norms. Table VIII presents the squared multiple correlations for the dependent variables of behavior and intentions for all final models.

\section{TABLE VIII}

SQUARED MULTIPLE CORRELATIONS FOR BEHAVIOR AND INTENTIONS IN ALL MODELS

\begin{tabular}{|llll|}
\hline MODEL & BEHAVIOR & INTENTIONS \\
Ajzen's Simultaneous (Fig. 10) & 0.339 & 0.277 \\
Variation of Ajzen (Fig. 11) & 0.329 & 0.829 \\
Expanded Simultaneous (Fig. 13) & 0.355 & 0.284 \\
Expanded Variation (Fig. 14) & 0.333 & 0.877 \\
\hline
\end{tabular}


CHAPTER V

\section{DISCUSSION}

The results of the model testing led to several important findings. Perhaps the most significant of these were that attitudes did not directly influence behaviors and intentions and that society-centered values affected selfreported behavior, subjective norms, attitudes and perceived behavioral control, either directly or indirectly.

The preliminary measurement analysis stage saw several questions drop out of the analysis. Two of these questions measured subjective norms about neighbors and two measured self-centered values. It was expected that neighbors' recycling would be a potent influence in this study. oskamp et al. (1991) found that the second strongest variable in predicting participation in curbside recycling was recycling by one's friends and neighbors. However, in the present study, $22.5 \%$ of the neighbor questions went unanswered by the respondents. This is a sharp contrast to oskamp's finding. It is interesting, that of the types of people asked about, neighbors had the highest no-response rate. Perhaps people do not know their neighbors well enough to answer these questions. But in the case of recycling, even if respondents did not know how their neighbors felt about 
recycling, participation by neighbors in curbside recycling is clearly visible on collection days when brightly colored bins line the curb. Perhaps people know that their neighbors recycle but, they have not talked to them specifically about recycling. Not knowing for sure what their neighbors thought may have led the respondents to be reluctant to answer these particular questions.

\section{THE MEASUREMENT OF MORAL OBLIGATION}

The moral obligation questions were unable to measure self-centered values as a separate construct from societycentered values. The question of whether people clearly express separate self-centered values and society-centered values was not resolved. The questions as asked in this study led to a single society-centered construct. However, a better way to measure the self-centered values might have been to state these in terms of personal gain. For example, a self-centered value might be to not recycle to avoid cleaning and storing recyclables and save time. The rephrasing of the self-centered values in this cost-benefit style would also place these values within the commons dilemma framework. Framed in this light, it would be more accurate to say that self-centered values is not a moral obligation variable, since it is a collection of evaluations based on selfish motives. 
The questions that measured whether people are recycling to save some aspect of the environment and that it makes them feel good loaded on the same factor. However, feeling good was hypothesized to be a self-centered value. This item's loading on the society-centered factor could mean that either the differentiation between these two types of values does not exist or that they feel good about recycling because it is something they can do to protect or preserve the environment. These results relate to past studies that have found that the most important reasons why people recycle are intrinsic motivation and personal satisfaction (De Young, 1986; De Young \& Kaplan, 1986). However, in this study, motivation and satisfaction appear to be derived from society-centered values.

Environmentalists most often mentioned the thought of having done something worthwhile and beneficial, not the economic advantages of recycling (De Young, 1986). This study supports those findings and suggests people in general feel similar to the environmentalists.

\section{STRUCTURAL MODELS}

In the structural phase of the analysis, there were several patterns of relationships that were common to all models. Attitudes, society-centered values and past behaviors maintain stable relationships throughout all models and in general, the results did not confirm Ajzen's 
model of behavior. The hypothesis that subjective norms would have a greater magnitude in influencing behavior was not supported. Instead, perceived behavioral control had the strongest path of influence on behavior. In addition, the results supported the proposition that the inclusion of a moral obligation variable would improve the prediction of behavior and intentions.

Although the models tested led to similar results, Figure 14 is the preferred model. Of the models in which behavior affected intentions, the Figure 14 model had the largest PGFI. The squared multiple correlations of this model, as compared to the comparable Ajzen model (Figure 14 vs. Figure 11 models), were larger for both behavior and intentions. This indicates that including moral obligation increases the amount of variance in behavior and intentions explained by the model. Discussion of the role individual variables play in predicting recycling behavior will be based on the Figure 14 model.

Subjective norms

Ajzen and Driver (1992) found that the influence of subjective norms was significant for only two of five leisure behaviors and even in these two cases, subjective norms did not significantly increase the explained variance and had a minor effect on the multiple correlations. A similar pattern was found in this study, although not hypothesized. Subjective norms influenced both intentions 
and behavior. The hypothesis that subjective norms would have a greater weight than other variables in influencing intentions and behavior was not supported. The path from subjective norms did not yield an appreciable impact on intentions. The low positive weight $(b=0.130)$ of that path would indicate that the more people perceive that others think they should recycle and the more people desire to do what others think, the greater the intention to recycle would be. However, given the small magnitude of the path, it has little influence on increasing intentions.

Perceived behavioral control

Perceived behavioral control had the strongest direct influence on behavior. These results indicate that a person will increase their recycling behavior if they perceive an increased level of control over performing a recycling behavior. Similar results were found in Alagna and Reddy's study of women's performance of breast self-exam (1984). The correlation of perceived behavioral control with the frequency of self-examinations was 0.45 ; the correlation of proficiency at the behavior with the actual performance of the behavior was 0.57 . In general, people's attempts to perform a behavior is commensurate with the amount of confidence they have in their ability to actually do so. As they become more capable of performing the behavior, their attempts become more successful. 
$\underline{\text { Attitudes }}$

Attitudes did not directly influence either behavior or intentions, however, it was correlated with the independent variables in the model. This component of Ajzen's model has also not been supported by other studies. Several studies have not shown a link between attitude and behavior. For example, attitudes made no significant direct contributions to the prediction of leisure behaviors (Ajzen \& Driver, 1992). In the present study, the effect of attitude on behavior and intentions is not direct but, it is correlated with subjective norms and perceived behavioral control which in turn is correlated with intentions and behavior.

In the present study, attitude's lack of influence may be the result of the measurement strategy. The positive and negative values which were used to evaluate attitudes towards cleaning, sorting and preparing materials for recycling were values which were often mentioned by participants in past recycling studies. This measurement strategy may have been too general to invoke attitudes towards specific acts of recycling behavior and may have diluted the magnitude of attitude's affect upon intentions and behavior. 
$\underline{\text { Society-centered values }}$

The society-centered aspect of moral obligation directly influenced behavior but not intentions. Societycentered norms affected all of the predecessor variables to behavior and intentions. In other words, as societycentered values increases, perceived behavioral control, attitude, subjective norms and self-reported recycling behavior also increases.

This study's hypothesis that moral obligation would enhance prediction of the model was shown true, however, the variable's role was different than originally hypothesized. The construct, society-centered values, was hypothesized to affect intentions. The influence of society-centered values upon behavior and perceived behavioral control was not hypothesized.

Since Ajzen's model is based on beliefs and evaluations, it seems reasonable that moral obligation influences a person's beliefs and evaluations about subjective norms, attitudes and perceived behavioral control. However, it is perplexing that moral obligations should influence behavior and not intentions. Neither behavior nor intentions is composed of beliefs and evaluations. Perhaps people are willing to do more recycling and do not see it as a sacrifice when they compare it to the impact their behavior can have on large-scale issues such as preserving future resources and community 
landfill space. This pattern of findings is not unique to this study. A study by Beck and Ajzen (1991) to predict dishonest behavior included perceived moral obligation when predicting lying, cheating and shoplifting. It aided in the prediction of lying behaviors but, not in the prediction of intentions.

The influence of society-centered values upon subjective norms, attitudes and perceived behavioral control $(b=0.408,0.550$ and -0.453 , respectively $)$ were the strongest paths in the model. They indicate that increased levels of moral obligation enhanced these variables. The direct effect of moral obligation on behavior was weak (0.175), suggesting that even though increased levels of moral obligation would increase behavior, it would not have a large direct impact but instead a large indirect effect.

\section{Past behavior}

In the expanded models, past behavior did not significantly relate to any of the variables in the models. Past behavior's lack of significant influence and very low correlations with the other independent variables indicate that past recycling behavior cannot predict intentions or behavior. There are several possible explanations for this result. First, it could be that recycling is a change in people's lifestyles that is not dependent upon their past behavior. In this study, the responses showed increasing levels of recycling as compared to one month ago, six months 
ago and one year ago. Compared to one month ago, $79.2 \%$ of the respondents said they recycled at the same level. Compared to six months ago, $47.2 \%$ recycled at the same level, 34.38 recycled slightly more and $14.5 \%$ had increased their recycling greatly. In comparison to one year ago, only 19.58 said their levels remained the same, 30.48 said they had increased slightly and 46.98 said they had increased greatly. Even though there is variation in the rate that people increased their level of recycling, there is no indication that these changes have a relationship with current recycling behavior or intentions. Perhaps it is not the change in past behavior but rather the past behavior itself that is important. A different measurement strategy would be needed to test this possibility.

Another possible explanation for the failure of past behavior to influence current behavior is that the survey's past behavior questions were measuring levels of past behavior differently than behavior and intentions were being measured. The measure of past behavior requested that the respondent estimate a general sense of past and current recycling behavior. Behavior and intentions asked about recycling of individual items. Past behavior of particular items might be more predictive of current recycling behavior of those items. 
Behavior and intentions

The high correlation between behavior and intention indicates that what people are doing now is what they intend to do in the future. There appears to be no future plan to change. It is not clear how one would change intentions, given that the only other direct path, besides behavior, is a weak path from subjective norms (0.130). Recycling behavior appears to be influenced by perceived behavioral control and subjective norms. Increasing perceived behavioral control leads to better recycling. The more others think you should recycle and the more you want to follow their norms, the greater recycling behavior. As just discussed, social norms directly effects behavior only minimally and has a strong indirect effect.

\section{APPLICATION OF THE RESULTS}

In attempting changes in recycling behavior, it is important to understand the factors influencing current behaviors. This study identified factors and their relationships which provide clues as to the type of interventions that would be effective. Programs aiming to improve recycling behaviors should focus their attempts in the areas of perceived behavioral control and societycentered values.

The role of perceived behavioral control suggests that campaigns aimed at encouraging recycling behaviors would do 
well to focus on how one actually does recycling. To increase levels of internal perceived behavioral control, informative flyers should describe how to prepare items. For example, cans should be washed and have their labels removed and ends cut out. Or, aluminum can be identified by the fact that it does not stick to a magnet and should be separated from tin cans. These "how to's" will increase the level of perceived behavioral control, which in turn will increase recycling according to the findings of this study. An education strategy is consistent with the suggestions of other studies (Sia, Hungerford \& Tomera, 1985-86; Hines, Hungerford \& Tomera, 1986-87). External perceived behavioral control can be increased by supplying the necessary services and information about them to the resident.

Another influential variable is society-centered values. An ad campaign could focus on the society-centered reasons to recycle--to preserve resources for future generations, to maintain landfill availability, to save energy. The campaign could translate an individual's recycling efforts into the quantative effects on the environment. For example, recycling a one month's supply of daily newspapers yields a three foot stack of papers which equals a 20' tall tree. Also, slogans, such as "Recycle for a better tomorrow," could incorporate these society-centered values. In turn, this would positively affect subjective 
norms, attitudes and perceived behavioral control which will improve recycling behaviors.

Society-centered values and perceived behavioral control are the two variables which impacted behavior and can also be manipulated fairly easily. Focusing on what others are doing to recycle will affect subjective norms and possibly intentions but, this is not easily manipulated since reference groups vary so greatly. Campaigns focused on changing attitudes about recycling would appear to have a minor indirect impact and may not achieve the desired effects.

\section{CRITICISMS OF THE STUDY}

There are several criticisms of this study. The most obvious weakness was that the measurement of behavior and intention was being taken at the same point in time. Although the models were adjusted to accommodate this, it is hard to verify Ajzen's hypothesized patterns of influence from intentions to behavior. Future research should include a second measurement time point to determine what, if any, changes over time exist.

The self-reporting of recycling behaviors also presents a weak point in the study. Physical measurements of the behaviors, such as the number of cans and bottles and pounds of paper recycled, would strengthen the measurement of the behavior variable. This would require the cooperation of 
the subjects, since materials measured would include not only items recycled at the curb but, also at depots and any other place the subject would be inclined to take the materials. Perhaps an easier measure of actual recycling behavior would be to measure the amounts of recyclable materials that the subject threw away as garbage. This would supply a truer measure of waste reduction behaviors. The relationship between behavior and its antecedent variables could be expected to decrease with the elimination of self-report bias.

An improvement to the measurement of past behavior would be to measure it in a different manner. Measurement of individual behaviors, such as what percentage of your newspaper did you recycle one year ago, might supply a better indication of past behaviors rather than asking for a general sense of how much one recycled last year compared to this year.

Several respondents commented that a subjective norms question should have focused on what they thought they should be doing instead of what others thought they should be doing. Questions that tap a personal norm construct could be compared to subjective norm measures. There it could be determined which has a greater influence on behavior.

Finally, stratifying across groups of poor, average or diligent recyclers would allow the differential patterns in 
these groups to be better examined. Stronger effects may have been realized if this method had been applied. 
REFERENCES

Ajzen, I. 1991. The theory of planned behavior. Organizational Behavior and Human Decision Processes, 50, 179-211.

Ajzen, I. 1988. Attitudes, personality, and behavior. Chicago: Dorsey Press.

Ajzen, I. 1987. Attitudes, traits, and actions: Dispositional prediction of behavior in personality and social psychology. In L. Berkowitz (Ed.) Advances in experimental social psychology, 20, San Diego: Academic Press.

Ajzen, I. 1985. "From intentions to actions: A theory of planned behavior." In J Kuhl \& J. Beckmann (Eds.), Action-control: From cognition to behavior, (pp. 1139) Heidelberg-Springer.

Ajzen, I. 1971. Attitudinal vs. normative messages: An investigation of the differential effects of persuave communications on behavior. Sociometry, 34, 263-280.

Ajzen, I., \& Driver, B. L. 1992. Application of the theory of planned behavior to leisure choice. Journal of Leisure Research, 3, 207-224.

Ajzen, I., \& Driver, B. L. 1991. Prediction of leisure participation from behavioral, normative, and control beliefs: An application of the theory of planned behavior. Journal of Leisure Sciences, 13(3), 185-204.

Ajzen, I., \& Fishbein, M. 1980. Understanding attitudes and predicting social behavior. Englewood-cliffs, N.J.: Prentice-Hall.

Ajzen, Icek, \& Madden, T. J. 1986. Prediction of goaldirected behavior: The role of intention, perceived control, and prior behavior. Journal of Experimental Social Psychology, 22, 453-474.

Alagna, S. W., \& Reddy, D. M. 1984. Predictors of proficient technique and successful lesion detection in breast self-examination. Health Psychology, 3, 113127 . 
Ajzen, I., \& Timko, C. 1986. Correspondence between health attitudes and behavior. Journal of Basic and Applied Social Psychology, 7, 259-276.

Ajzen, I., Timko, C. \& \& White, J. B. 1982. Self-monitoring and the attitude-behavior relation. Journal of Personality and Social Psychology, 42, 426-435.

Allen, G. H. 1972. How deep is environmental awareness? Journal of Environmental Education, 3, 1-3.

Asch, J. \& Shore, B. M. 1975. Conservation bvehavior as the outcome to environmental education. Journal of Environmental Education, 6, 25-33.

Bandura, A. 1986. Social foundations of thought and action: A social cognitive theory. Englewood Cliffs, NJ: Prentice-Hall.

Bandura, A. 1982. Self-efficacy mechanism in human agency. American Psychologist, 37, 122-147.

Bandura, A. 1977. Social learning theory. Englewood Cliffs, NJ: Prentice-Hall.

Bandura, A. 1977. Self-efficacy: Toward a unifying theory of behavioral change. Psychological Review, 84, 191215 .

Beck, L., \& Ajzen, I. 1991. Predicting dishonest actions using the theory of planned behavior. Journal of Research in Personality, 25(3), 285-301.

Bel1, P. A., Peterson, T. R., \& Hautaluoma, J. E. 1989. The effect of punishment probability on overconsumption and stealing in a simulated commons. Journal of Applied Social Psychology, 19, 1483-1495.

Bentler, P. M., \& Bonett, D. G. 1980. Significance tests and goodness of fit in the ananlysis of covariance structures. Psychological Bulletin, 88, 588-606.

Bentler, P. M., \& Speckart, G. 1979. Models of attitudebehavior relations. Psychological Review, 86, 452464 .

Bentler, P. M., \& Speckart, G. 1981. Attitudes "cause" behavior: A structural equation analysis. Journal of Personality and Social Psychology, 40, 226-238. 
Brewer, M. B., \& Kramer, R. M. 1986. Choice behavior in social dilemmas: Effects of social density, group size, and decision framing. Journal of Personality and Social Psychology, 50, 543-549.

Budd, R. J., North, D., \& Spencer, C. 1984. Understanding seat belt use: A test of Bentler and speckart's extension of the theory of reasoned action. European Journal of Social Psychology, 14, 69-78.

Cohen, M. R. 1973. Environmental information vs. environmental attitudes. Journal of Environmental Education, $\underline{5}, 5-8$.

Cole Publications. 1992. Cole's Reference Directory: Greater Portland, 1992 Issue. Portland, OR: Cole Publications.

Cone, J. D., \& Hayes, S. C. 1980. Environmental problems/behavioral solutions. Monterey, CA: Brooks/Cole.

Davidson-Cummings, L. 1977. Voluntary strategies in the environmental movement: Recycling as cooptation. Journal of Voluntary Action Research, 6, 153-160.

Dawes. R. M. 1980. Social dilemmas. Annual Review of Psychology, 31, 169-193.

De Young, R. 1986. Some psychological aspects of recycling: The structure of conservation satisfactions. Environment and Behavior, 18, 435-449.

De Young, R. , \& Kaplan, S. 1986. Conservation behavior and the structure of satisfactions. Journal of Environmental Systems, 15, 233-242.

Deslauriers, B. C., \& Everett, P. B. 1977. Effects of intermittent and continuous token reinforcement on bus ridership. Journal of Applied Psychology, 62, 360-375.

Dunlap, R. E., Grieneeks, J. K. \& Rokeach, M. 1983. Human values and pro-environmental behavior. In C. Seligman, Environmental ethics, Journal of Social Issues, 1989, $\underline{45}(1), 169-184$.

Edney, J. J. 1980. The commons problem: Alternative perspectives. American Psychologist, 35, 131-150.

Edney, J. J. 1979. The nuts game: A concise commons dilemma analogue. Environmental Psychology and Nonverbal Behavior, 3, 252-254. 
Edney, J. J., \& Harper, C. S. 1978a. Heroism in a resource crisis: A simulation study. Environmental Management, 2, 523-527.

Edney, J. J. \& Harper, C. S. 1978b. The effects of information in a resource management problem: A social trap analog. Human Ecology, 6 , 387-395.

Fredricks, A.J., \& Dossett, D. L. 1983. Attitude-behavior relations: A comparison of the Fishbein-Ajzen and the Bentler-Speckhart models. Journal of Personality and Social Psychology, 45, 501-512.

Geller, E. S., Winnett, R. A., \& Everett, P. B. 1982. Reserving the environment: New strategies for behavior change. New York: Pergamon.

Gorsuch, R. L., \& ortberg, J. 1983. Moral obligation and attitudes: Their relation to behavioral intentions. Journal of Personality and Social Psychology, 44, 10251028 .

Granrose, C. S. 1984. A Fishbein-Ajzen model of intention to work following childbirth. Journal of Vocational Behavior, 25(3), 359-372.

Hayes, S. C., \& Cone, J. D. 1977a. Reducing residential electrical energy use: Payments, information and feedback. Journal of Applied Behavior Analysis, 10, $425-435$.

Hayes, S. C., \& Cone, J. D. 1977b. Decelerating environmentally destructive lawn-walking behavior. Environment and Behavior, 9, 511-534.

Hines, J., Hungerford, H., \& Tomera, A. 1986-87. Analysis and synthesis of research on responsible environmental behavior: A meta analysis. Journal of Environmental Education, 18(2), 1-8.

Hopper, J. R., \& Nielsen, J. M. 1991. Recycling as altruistic behavior: Normative and behavioral strategies to expand participation in a community recycling program. Environment and Behavior, 23 (2), $195-220$.

King, G. W. 1975. An analysis of attitudinal and normative variables as predictors of intentions and behavior. Speech Monographs, 42, 237-244. As in Ajzen, I., Attitudes, Personality, and Behavior, 1988, p. 120, Chicago: Dorsey Press. 
Kohlenberg, R., Phillips, T., \& Proctor, W. 1976. A behavioral analysis of peaking in residential electrical energy consumers. Journal of Applied Behavior Analysis, 9, 13-18.

Komorita, S. S. 1987. Cooperative choice in decomposed social dilemmas. Personality and Social Psychology Bulletin, 13, 53-63.

Manstead, A. S. R., Proffitt, C. \& Smart, J. L. 1983. Predicting and understanding mothers' infant-feeding intentions and behavior: Testing the theory of reasoned action. Journal of Personality and Social Psychology, 44, 657-671.

Moore, S. F., Shaffer, L. S., Pollak, E. L., \& Taylor-Lemke, P. 1987. The effects of interpersonal trust and prior common problem experience on commons management. Journal of Social Psychology, 127, 19-29.

Mulaik, S. A., James, L. R., Van Alstine, J., Bennett, N., Lind, S., \& Stilwell, C. D. 1989. Evaluation of goodness-of-fit indices for structural equation models. Psychological Bulletin, 105(3), 430-445.

Netemeyer, R. G., \& Burton, S. 1990. Examining the relationships between voting behavior, intention, perceived behavioral control, and expectation. Journal of Applied Social Psychology, 20, 8, 661-690.

Platt, J. 1973. Social traps. American Psychologist, 28, $641-651$.

Rokeach, M. 1968. Beliefs, attitudes, and values. San Francisco: Jossey-Bass.

Rokeach, M. 1973. The nature of human values. New York: Free Press.

Schifter, D. B., \& Ajzen, I. 1985. Intention, perceived control, and weight loss: An application of the theory of planned behavior. Journal of Personality and Social Psychology, 49, 843-851.

Schnelle, J. F., Gendrich, J. G., Beegle, G. P., Thomas, M. M., \& MCNess, M. P. 1980. Mass media techniques for prompting behavior change in the community. Environment and Behavior, 12, 157-166. 
Seligman, C. 1989. Environmental ethics. Journal of Social Issues, 4ㄷ⑴, 169-184.

Sia, A., Hungerford, H., \& Tomera, A. 1985-86. Selected predictors of responsible environmental behavior: An analysis. Journal of Environmental Education, 17(2), $31-40$.

Smetana, J. B. \& Adler, N. E. 1980. Fishbein's value $\mathrm{x}$ expectancy model: An examination of some assumptions. Personality and Social Psychology Bulletin, 6 , 89-96.

van Ryn, M., \& Vinokur, A. D. 1990. The role of experimentally manipulated self-efficacy in determining job-search behavior among the unemployed, in Ajzen, I., The theory of planned behavior, Organizational Behavior and Human Decision Processes, 1991, 50, 179-211.

Vinokur-Kaplan, D. 1978. To have - or not to have another child: Family planning attitudes, intentions, and behavior. Journal of Applied Social Psychology, 8 , $29-46$.

Wallston, K. A., Wallston, B. S., \& DeVillis, R. 1978. Development of the multidimensional health locus of control (MHLC) scales. Health Education Monographs, $\underline{6}$, 161-170. As in Ajzen, I., Attitudes, personality, and behavior, 1988, Chicago: Dorsey Press.

Winett, R. A., \& Nietzel, M. T. 1975. Behavioral ecology: Contingency management of consumer energy use. American Journal of Community Psychology, 3, 123-133.

Yamagishi, T. 1986. The provision of a sanctioning system as a public good. Journal of Personality ans Social Psychology, 51, 110-116. 
APPENDIX 
RECYCLING QUESTIONNAIRE

Section 1.

1. Do you recycle any materials at home? _ yes _ no

2. Using the scale below, how often have you recycled the following items in the last month?

\begin{tabular}{||c|c|c|c|c|}
\hline 1 & \multicolumn{1}{|c|}{2} & \multicolumn{1}{|c|}{3} & 4 & 5 \\
\hline $\begin{array}{l}\text { Rarely/ } \\
\text { Never }\end{array}$ & $\begin{array}{l}\text { About 25\% } \\
\text { of the } \\
\text { time }\end{array}$ & $\begin{array}{l}\text { About 50\% } \\
\text { of the } \\
\text { time }\end{array}$ & $\begin{array}{l}\text { About 75\% } \\
\text { of the time }\end{array}$ & Always \\
\hline
\end{tabular}

Please circle only one number per item.

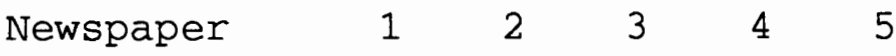

$\begin{array}{llllll}\text { Cardboard } & 1 & 2 & 3 & 4 & 5\end{array}$

$\begin{array}{llllll}\text { Aluminum } & 1 & 2 & 3 & 4 & 5\end{array}$

$\begin{array}{llllll}\text { Tin } & 1 & 2 & 3 & 4 & 5\end{array}$

$\begin{array}{llllll}\text { Glass } & 1 & 2 & 3 & 4 & 5\end{array}$

$\begin{array}{llllll}\text { Plastic } & 1 & 2 & 3 & 4 & 5\end{array}$

$\begin{array}{llllll}\text { Yard Debris } & 1 & 2 & 3 & 4 & 5\end{array}$

$\begin{array}{llllll}\text { Magazines } & 1 & 2 & 3 & 4 & 5\end{array}$

Household hazardous

$\begin{array}{llllll}\text { waste } & 1 & 2 & 3 & 4 & 5\end{array}$

Paper

(scrap, white) $1 \quad 2 \quad 3 \quad 4 \quad 5$

$\begin{array}{llllll}\text { Other } & 1 & 2 & 3 & 4 & 5\end{array}$

(please specify

3. Using the scale above, how often do you bring recyclables home from outings so that you can recycle them?

$\begin{array}{lllll}1 & 2 & 3 & 4 & 5\end{array}$


For the next three items, please circle the numbers of the responses which best completes the statements.

\begin{tabular}{||c|c|c|c|c|}
\hline 1 & 2 & 3 & 4 & 5 \\
\hline $\begin{array}{l}\text { Decreased } \\
\text { greatly }\end{array}$ & $\begin{array}{l}\text { Decreased } \\
\text { slightl }\end{array}$ & $\begin{array}{l}\text { Remained } \\
\text { the same }\end{array}$ & $\begin{array}{l}\text { Increased } \\
\text { slightl }\end{array}$ & $\begin{array}{l}\text { Increased } \\
\text { greatly }\end{array}$ \\
\hline
\end{tabular}

4. Compared to 1 month ago, my present level of recycling has:

$$
\begin{array}{lllll}
1 & 2 & 3 & 4 & 5
\end{array}
$$

5. Compared to 6 months ago, my present level of recycling has:

$$
\begin{array}{lllll}
1 & 2 & 3 & 4 & 5
\end{array}
$$

6. Compared to 1 year ago, my present level of recycling has:

$$
\begin{array}{lllll}
1 & 2 & 3 & 4 & 5
\end{array}
$$

7. Have you had any change in recycling services within the last year?

$$
\text { yes }
$$$$
\text { no }
$$

If yes,

please check any that apply. yard debris is being collected additional item being collected item no longer being collected other (Please describe) 
Section 2 .

1. Using the following scale, please indicate how likely it is that you will recycle each of the following items during the next month.

\begin{tabular}{|l|c|c|c|c|c|c|}
\hline 1 & 2 & 3 & 4 & 5 & 6 & None \\
\hline $\begin{array}{l}\text { Extremely } \\
\text { Unlikely }\end{array}$ & Unlikely & $\begin{array}{l}\text { Somewhat } \\
\text { Unlikely }\end{array}$ & $\begin{array}{l}\text { Somewhat } \\
\text { Likely }\end{array}$ & Likely & $\begin{array}{l}\text { Extremely } \\
\text { Likely }\end{array}$ & $\begin{array}{l}\text { Don't } \\
\text { have } \\
\text { any to } \\
\text { recycle }\end{array}$ \\
\hline
\end{tabular}

\begin{tabular}{|c|c|c|c|c|c|c|c|}
\hline Newspaper & 1 & 2 & 3 & 4 & 5 & 6 & None \\
\hline Cardboard & 1 & 2 & 3 & 4 & 5 & 6 & None \\
\hline Glass & 1 & 2 & 3 & 4 & 5 & 6 & None \\
\hline Tin & 1 & 2 & 3 & 4 & 5 & 6 & None \\
\hline Aluminum & 1 & 2 & 3 & 4 & 5 & 6 & None \\
\hline $\begin{array}{l}\text { Yard } \\
\text { debris }\end{array}$ & 1 & 2 & 3 & 4 & 5 & 6 & None \\
\hline Plastic & 1 & 2 & 3 & 4 & 5 & 6 & None \\
\hline Magazines & 1 & 2 & 3 & 4 & 5 & 6 & None \\
\hline $\begin{array}{l}\text { Household } \\
\text { hazardous }\end{array}$ & $\begin{array}{l}1 \\
\text { waste }\end{array}$ & $e^{2}$ & 3 & 4 & 5 & 6 & None \\
\hline $\begin{array}{l}\text { Paper } \\
\text { (scrap, wh }\end{array}$ & hite) & 2 & 3 & 4 & 5 & 6 & None \\
\hline
\end{tabular}

Other

$\begin{array}{lllllll}1 & 2 & 3 & 4 & 5 & 6 & \text { None }\end{array}$

2. Using the following scale, please indicate how likely it is that you will bring home recyclables from outings so that you can recycle them.

\begin{tabular}{|l|c|c|c|c|c|c|}
\hline 1 & 2 & 3 & 4 & 5 & 6 & None \\
\hline $\begin{array}{l}\text { Extremely } \\
\text { Unlikely }\end{array}$ & Unlikely & $\begin{array}{l}\text { Somewhat } \\
\text { Unlikely }\end{array}$ & $\begin{array}{l}\text { Somewhat } \\
\text { Likely }\end{array}$ & Likely & $\begin{array}{l}\text { Extremely } \\
\text { Likely }\end{array}$ & $\begin{array}{l}\text { No } \\
\text { planned } \\
\text { outings }\end{array}$ \\
\hline
\end{tabular}


Section 3 .

Using the following scale, please indicate the extent to which you agree or disagree with each statement.

\begin{tabular}{|c|c|c|c|c|c|}
\hline 1 & 2 & 3 & 4 & 5 & 6 \\
\hline $\begin{array}{l}\text { Strongly } \\
\text { Disagree }\end{array}$ & Disagree & $\begin{array}{l}\text { SIightly } \\
\text { Disagree }\end{array}$ & $\begin{array}{l}\text { Slightly } \\
\text { Agree }\end{array}$ & $\begin{array}{l}\text { Agree } \\
\text { Somewhat }\end{array}$ & $\begin{array}{l}\text { Strongly } \\
\text { Agree }\end{array}$ \\
\hline
\end{tabular}

1. My $\frac{\text { immediate family think }}{1} \underset{4}{2} \underset{5}{\text { I }} \underset{6}{2}$ should recycle.

2. My neighbors think I should recycle.

$$
\begin{array}{llllll}
1 & 2 & 3 & 4 & 5 & 6
\end{array}
$$

3. My closest friends think I should recycle.

4. The environmentalists think I should recycle.

5. Most government officials think I should recycle.

$$
\begin{array}{lllll}
1 & 2 & 3 & 4 & 5
\end{array}
$$

Using the following scale, please indicate the number which best reflects your feelings.

\begin{tabular}{|c|c|c|c|c|c|}
\hline 1 & 2 & 3 & 4 & 5 & 6 \\
\hline $\begin{array}{l}\text { Strongly } \\
\text { Disagree }\end{array}$ & Disagree & $\begin{array}{l}\text { Slightly } \\
\text { Disagree }\end{array}$ & $\begin{array}{l}\text { Slightly } \\
\text { Agree }\end{array}$ & $\begin{array}{l}\text { Agree } \\
\text { Somewhat }\end{array}$ & $\begin{array}{l}\text { Strongly } \\
\text { Agree }\end{array}$ \\
\hline
\end{tabular}

6. Generaliy speaking, I want to do what my immediate family think I should do when it comes to recycling.

$$
\begin{array}{llllll}
1 & 2 & 3 & 4 & 5 & 6
\end{array}
$$

7. Generally speaking, I want to do what my neighbors think I should do when it comes to recycling.

$$
\begin{array}{llllll}
1 & 2 & 3 & 4 & 5 & 6
\end{array}
$$

8. Generally speaking, I want to do what my closest friends think I should do when it comes to recycling.

$$
\begin{array}{llllll}
1 & 2 & 3 & 4 & 5 & 6
\end{array}
$$

9. Generally speaking, I want to do what the environmentalists think I should do when it comes to recycling.

$$
\begin{array}{llllll}
1 & 2 & 3 & 4 & 5 & 6
\end{array}
$$


10. Generally speaking, I want to do what most government officials think I should do when it comes to recycling. 
Section 4 .

Now I'd like to know what you think about recycling in general. How would you rate the following statement for each pair of words? Please circle one number between 1 and 7 that is closest to your feelings.

1. Cleaning, sorting and preparing materials for recycling is:

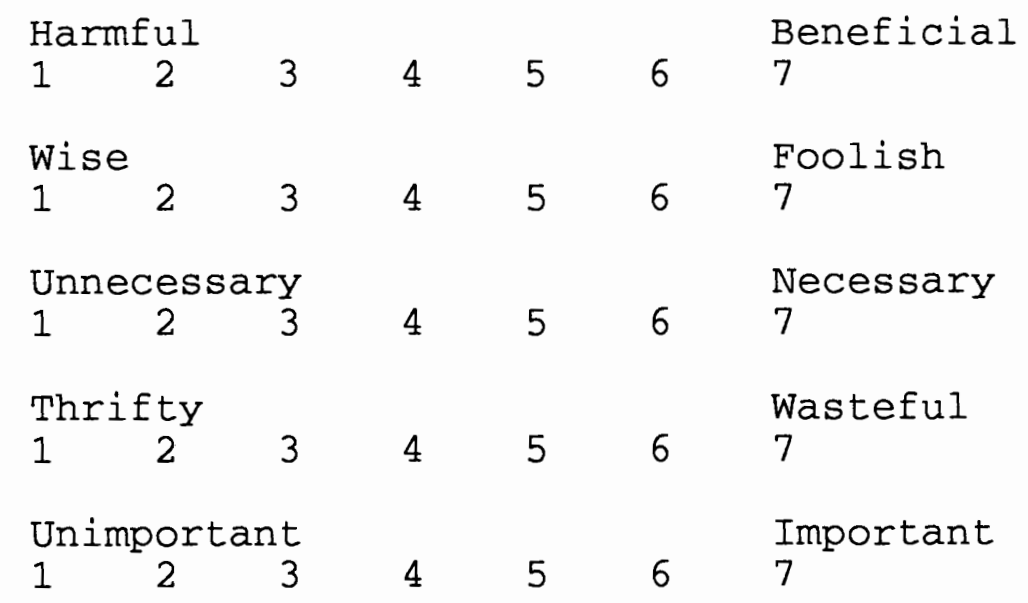

2. How much control do you have over whether you do or do not recycle every month?

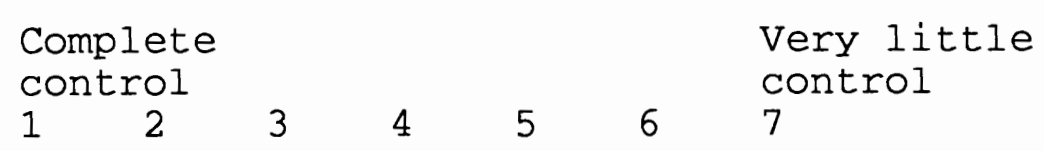

3. For me to recycle my paper, cans, and bottles every week is:

$$
\begin{array}{lllllll}
\text { Easy } & & & & & & \text { Difficult } \\
1 & 2 & 3 & 4 & 5 & 6 & 7
\end{array}
$$

4. If I wanted to, I could prepare my recyclables properly and get them out to be collected.

$\begin{array}{lllllll}\begin{array}{l}\text { Strongly } \\ \text { Agree }\end{array} & & & & & \begin{array}{l}\text { Strongly } \\ \text { Disagree }\end{array} \\ 1 & 2 & 3 & 4 & 5 & 6 & 7\end{array}$

Any comments? 
Section 5 .

Below are some reasons why you may or may not recycle. Using the following scale, please indicate the extent to which you agree or disagree with each statement. Circle only one number per statement.

\begin{tabular}{||l|l|l|l|l|l|}
\hline 1 & 2 & 3 & 4 & 5 & 6 \\
\hline $\begin{array}{l}\text { Strongly } \\
\text { Disagree }\end{array}$ & $\begin{array}{l}\text { Disagree } \\
\text { Somewhat }\end{array}$ & $\begin{array}{l}\text { Slightly } \\
\text { Disagree }\end{array}$ & $\begin{array}{l}\text { Slightly } \\
\text { Agree }\end{array}$ & $\begin{array}{l}\text { Agree } \\
\text { Somewhat }\end{array}$ & $\begin{array}{l}\text { Strongly } \\
\text { Agree }\end{array}$ \\
\hline
\end{tabular}

1. I recycle because it helps preserve our limited natural resources for future generations by re-using limited resources. $\begin{array}{llllll}1 & 2 & 3 & 4 & 5 & 6\end{array}$

2. I recycle because I can receive money for some recyclable

items (e.g. aluminum cans, paper).

$$
\begin{array}{llllll}
1 & 2 & 3 & 4 & 5 & 6
\end{array}
$$

3. I recycle because my recycling helps to save energy that would be needed to make brand new products.

$$
\begin{array}{llllll}
1 & 2 & 3 & 4 & 5 & 6
\end{array}
$$

4. I recycle because recycling saves me money on my garbage bill.

$$
\begin{array}{llllll}
1 & 2 & 3 & 4 & 5 & 6
\end{array}
$$

5. I recycle because it helps to reduce the amount of garbage that goes into the community landfilis.

$$
\begin{array}{llllll}
1 & 2 & 3 & 4 & 5 & 6
\end{array}
$$

6. I recycle because it makes me feel good.

$$
\begin{array}{llllll}
1 & 2 & 3 & 4 & 5 & 6
\end{array}
$$

Any comments? 
Section 6 .

1. What type of residence do you live in?

$$
\text { _ single family }
$$$$
\text { ___ other (___ }
$$

2. Do you rent or own your residence? rent own

3. How many people live in your residence?

4. How many children under the age of 18 live in your residence?

5. What type(s) of recycling services, if any, are available to you?

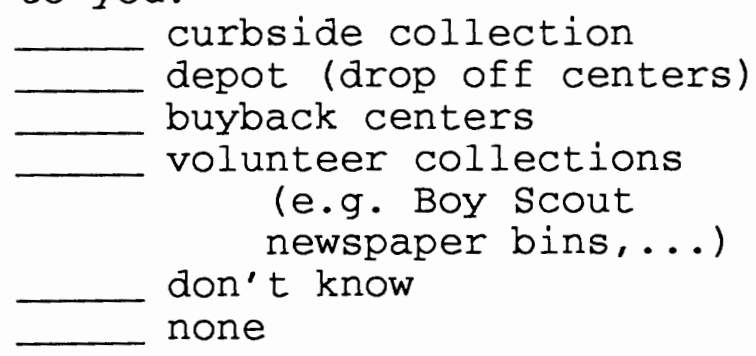

6. If you do have recycling services available to you, what types of items can be recycled? (Check all that apply). newspaper

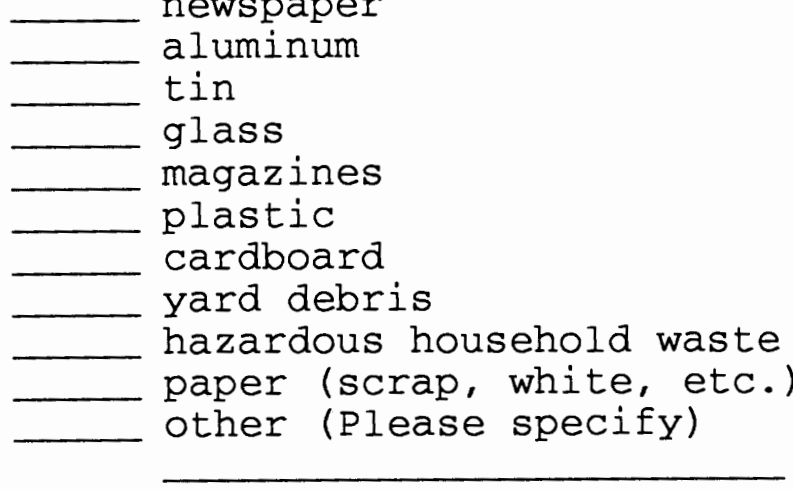

7. What street do you live on?

8. What is your zip code? 